Research Article

\title{
Numerical Investigation on Head and Brain Injuries Caused by Windshield Impact on Riders Using Electric Self-Balancing Scooters
}

\author{
Shi Shang $\mathbb{D}^{1,2}$ Yanting Zheng, ${ }^{1,3}$ Ming Shen, ${ }^{4}$ Xianfeng Yang, ${ }^{5}$ and Jun $X u\left(\mathbb{D}{ }^{1,2}\right.$ \\ ${ }^{1}$ Advanced Vehicle Research Center (AVRC), Beihang University, Beijing 100191, China \\ ${ }^{2}$ Department of Automotive Engineering, School of Transportation Science and Engineering, Beihang University, \\ Beijing 100191, China \\ ${ }^{3}$ Department of Transportation, School of Transportation Science and Engineering, Beihang University, Beijing 100191, China \\ ${ }^{4}$ Bioengineering Center, Wayne State University, Detroit, MI 48201, USA \\ ${ }^{5}$ Institute of Solid Mechanics, Beihang University, Beijing 100191, China \\ Correspondence should be addressed to Jun Xu; junxu@buaa.edu.cn
}

Received 17 August 2017; Revised 12 January 2018; Accepted 23 January 2018; Published 25 March 2018

Academic Editor: Jean Slawinski

Copyright (c) 2018 Shi Shang et al. This is an open access article distributed under the Creative Commons Attribution License, which permits unrestricted use, distribution, and reproduction in any medium, provided the original work is properly cited.

\begin{abstract}
To investigate head-brain injuries caused by windshield impact on riders using electric self-balancing scooters (ESS). Numerical vehicle ESS crash scenarios are constructed by combining the finite element (FE) vehicle model and multibody scooter/rider models. Impact kinematic postures of the head-windshield contact under various impact conditions are captured. Then, the processes during head-windshield contact are reconstructed using validated FE head/laminated windshield models to assess the severity of brain injury caused by the head-windshield contact. Governing factors, such as vehicle speed, ESS speed, and the initial orientation of ESS rider, have nontrivial influences over the severity of a rider's brain injuries. Results also show positive correlations between vehicle speed and head-windshield impact speeds (linear and angular). Meanwhile, the time of head-windshield contact happens earlier when the vehicle speed is faster. According to the intensive study, windshield-head contact speed (linear and angular), impact location on the windshield, and head collision area are found to be direct factors on ESS riders' brain injuries during an impact. The von Mises stress and shear stress rise when relative contact speed of head-windshield increases. Brain injury indices vary widely when the head impacting the windshield from center to the edge or impacting with different areas.
\end{abstract}

\section{Introduction}

The electric self-balancing scooter (ESS) has been attracting much attention because of its convenience and the increasing demand for modern portable transportation tools. The safety performance of ESS during traffic accidents has also been investigated because ESS riders have been considered as one group of vulnerable road users (VRUs). ESS riders may suffer from severe injuries during vehicle ESS accidents [1].

Scientists and engineers have continuously paid much attention to pedestrians/cyclists' head-brain injuries to investigate the impact mechanism and reduce casualties by designing pedestrian-friendly automobiles [2-4]. However, only a few studies on ESS safety have been conducted. Xu et al. $[5,6]$ first analyzed the ESS riders' head injuries caused by vehicular or ground impact. Under the same impact situation, the ESS rider's head impacts the windshield 20 60 ms later compared to the pedestrian.

The windshield contributes the highest frequency (32\%) of the head crash zone in vehicle-pedestrian accidents [7]. Previous studies intensively investigated the characteristics of head-windshield contacts $[8,9]$, such as head formwindshield impacts tests [10-12], responses of windshield $[3,13,14]$ (Alvarez and Kleiven [3] compared two kinds of windshield modelling approaches to capture the head form accelerations and windshield deformations from head 


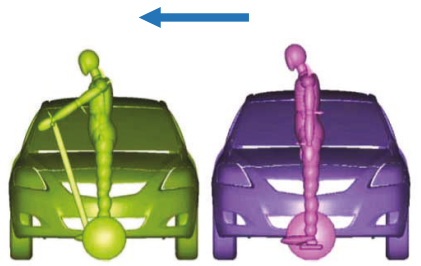

(a) Description of the baseline vehicle

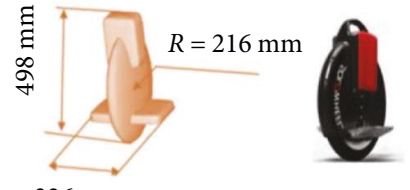

(b) Solowheel ESS model

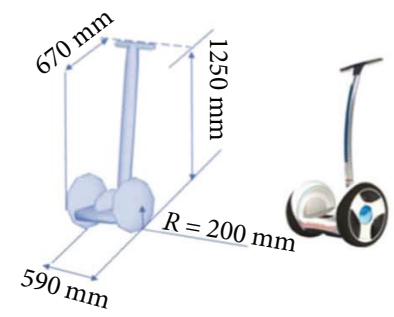

(c) Doublewheel ESS model

ESS accident scenario

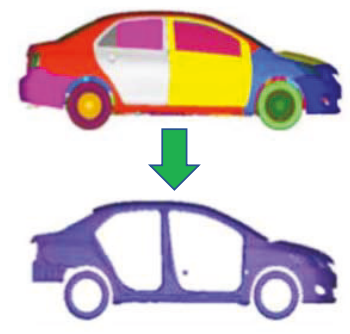

(d) Selected finite element (FE) vehicle model and simplified version

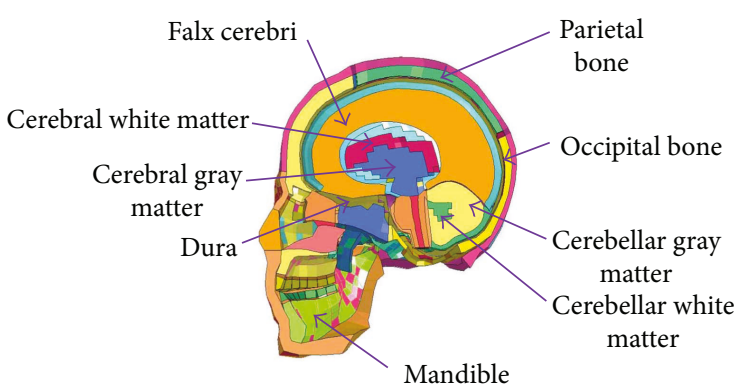

(e) Sectional view of the FE head model

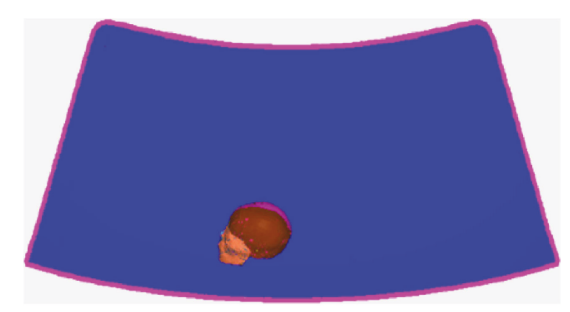

(f) A typical head-windshield impact scenario

FIgURe 1: Description of numerical models.

impacts and found that simple plasticity models of the windshield are not sufficient to predict that a nonlocal failure model [15] was needed), head-windshield contact reconstructions, and head injury analysis using FE methods [9, 16] (Mordaka et al. [17] analyzed three cases of pedestrian head-to-windshield impact accidents and performed additional parametric studies using a detailed FE model of the head). Results have confirmed that the severity of pedestrians/cyclists' head injuries is influenced by numerous factors involving vehicle speed [2,18] and vehicle type [19]. However, very few comparative studies about the ESS riders' head injuries caused by vehicles could be found. A preliminary study has been conducted in which the head injury of an ESS rider caused by windshield impact was examined [6]. The aim of the study is to evaluate the safety of electric self-balancing scooters (ESSs) through examining headbrain injuries caused by vehicle contact and understanding how the factors influence the effect on the severity of the ESS rider's brain injury.

\section{Materials and Methods}

2.1. Accident Scenario Setup. A two-phase simulation methodology is adopted to evaluate the ESS riders' brain injury caused by vehicle impact.

First, vehicle ESS rider impacts accident scenes are first numerically reconstructed are set up on MADYMO [20] platform (version 7.5), which is most commonly used in vehicle safety $[9,21,22]$. This multirigid body simulation basically provides the kinematics of the ESS rider which serves as the boundary conditions for the subsequent FE simulation. The lateral impact is set as the baseline vehicle ESS collision accident scenario, because this case accounts for the largest portion of vehicle VRU crashes in real-world accidents [9, 23]. The facing direction of the ESS rider is angled at $90^{\circ}$ to the direction of vehicle movement (Figure 1(a)). A continuous brake with $0.8 \mathrm{~g}$ deceleration, which assumed good contact friction between the tire and pavement [24], is adopted in all numerical models. The head-brain injuries of riders are examined comprehensively by varying the vehicle impact speed and ESS moving speed to represent diverse impact conditions.

Then, the biomechanical responses of the brain caused by head-windshield contact in vehicle ESS crash accident are examined. The processes of head-windshield contact are reconstructed and simulated using validated FE head [25] and windshield models [26] using LS-DYNA (version 971 R6.1.0). Similar simulation strategy was adopted in previous studies [9].

2.2. ESS Models. Two representative types of ESSs, namely, solowheel and doublewheel scooters, are selected and modeled as target scooters in the MADYMO platform. The multibody solowheel ESS model has one rigid body with three ellipsoids to depict its outer profile (Figure 1(b)), while the doublewheel ESS model has six ellipsoids to represent its profile (Figure 1(c)). A summary of the material stiffness values of the doublewheel and solowheel ESSs is listed in Tables 1 and 2, respectively. The friction coefficient between the ESS model and the pedestrian model was set as 0.3 . The friction coefficient for the ESS wheels against the ground is also set as 0.3 . The models, along with the parameters, have been applied in previous studies $[5,6]$. 
TABLe 1: Simplified force-deflection data of a doublewheel ESS model.

\begin{tabular}{|c|c|c|c|c|c|}
\hline \multicolumn{2}{|c|}{ Wheel } & \multicolumn{2}{|c|}{ Frame } & \multicolumn{2}{|c|}{ Handlebar } \\
\hline Deflection (m) & Force $(\mathrm{N})$ & Deflection (m) & Force $(\mathrm{N})$ & Deflection (m) & Force $(\mathrm{N})$ \\
\hline$\overline{0}$ & 0 & 0 & 0 & 0 & 0 \\
\hline 0.0015 & 4000 & 0.0012 & 1500 & 0.04 & 5000 \\
\hline \multirow[t]{6}{*}{0.002} & 9000 & 0.0054 & 2000 & 0.07 & 10,000 \\
\hline & & 0.0103 & 3000 & & \\
\hline & & 0.0161 & 4000 & & \\
\hline & & 0.0293 & 6500 & & \\
\hline & & 0.0358 & 6750 & & \\
\hline & & 0.055 & 6950 & & \\
\hline
\end{tabular}

TABle 2: Simplified force-deflection data of a solowheel ESS model.

\begin{tabular}{|c|c|c|c|c|c|}
\hline \multicolumn{2}{|c|}{ Wheel } & \multicolumn{2}{|c|}{ Pedal } & \multicolumn{2}{|c|}{ Board } \\
\hline Deflection (m) & Force $(\mathrm{N})$ & Deflection (m) & Force $(\mathrm{N})$ & Deflection (m) & Force $(\mathrm{N})$ \\
\hline 0 & 0 & 0 & 0 & 0 & 0 \\
\hline 0.0015 & 4000 & 0.0012 & 1500 & 0.04 & 5000 \\
\hline \multirow[t]{6}{*}{0.002} & 9000 & 0.0054 & 2000 & 0.07 & 10,000 \\
\hline & & 0.0103 & 3000 & & \\
\hline & & 0.0161 & 4000 & & \\
\hline & & 0.0293 & 6500 & & \\
\hline & & 0.0358 & 6750 & & \\
\hline & & 0.055 & 6950 & & \\
\hline
\end{tabular}

2.3. Human Model. The 50th percentile male pedestrian model of MADYMO human database [27] is chosen as the ESS rider human model for the process of vehicle ESS contact. The validated pedestrian model [28] is widely used in vehicle VRU accident simulations and analysis $[6,22]$ to predict the injury and capture the kinematic response. Both solowheel and doublewheel ESS riders were set as standing posture, as shown in Figure 1(a). The human model manual [27] may be used to obtain more detailed information on anthropometry, configuration and contact, and so on.

2.4. Vehicle Model. One of the most popular vehicles, sedan, is selected as the model car in the vehicle impact simulations. The FE model of the sedan was developed by the National Crash Analysis Center of George Washington University under a contract with the FHWA and NHTSA of the US DOT [29]. Only the outer surface of the vehicle front-end is needed for vehicle ESS rider contact, and the weight of the ESS with the human is trivial compared to that of the vehicle. Thus, the FE vehicle model is simplified (Figure 1(d)) to retain the outer profile to considerably save computation time [6]. In the MADYMO platform, the outer surface was employed as the rigid finite element and the original contact stiffness was kept. The contact types between the vehicle, ESS, and human are all set as a combined contact. Slave contact is applied for the type of human-ground contact and vehicle wheel-ground contact.

2.5. FE Head-Windshield Impact Model. The processes of head-windshield contacts are reconstructed using validated
FE windshield and human head model to extensively evaluate the head-brain injury of an ESS rider. This method has been frequently used in vehicle-pedestrian crash accident reconstructions $[9,30]$. The THUMS adult male 50th percentile pedestrian head is picked as the head model. The THUMS pedestrian model version 4.0 (the head model followed THUMS version 3.0 developed and validated by Kimpara et al. [25]) is developed by the Toyota Motor Corporation and Toyota Central R\&D Labs [31] based on real anthropometric parameters and cadaveric tests which may well represent an actual pedestrian involved in a traffic accident to investigate the safety problems. The head model contains skull, skin, scalp, cerebrum, cerebellum, mandible, teeth, meninges, and so on The cross-section of the THUMS head model in the median sagittal plane is shown in Figure 1(e).

The FE windshield model in this paper is adopted from $\mathrm{Xu}$ et al. and Yu et al. [26, 32]. The model has three layers, that is, the polyvinyl butyral (PVB) interlayer is sandwiched between two glass sheet layers. The thicknesses of the three layers from the outside to the inside faces of the windshield are $2.55 \mathrm{~mm}, 0.76 \mathrm{~mm}$, and $2.10 \mathrm{~mm}$, respectively. The glass model is modeled as a shell element, whereas the PVB interlayer is modeled as a solid element with a mesh size of $5 \mathrm{~mm} \times 5 \mathrm{~mm}$. A strain failure is added to the laminated windshield model (Table 3 ) to simulate a more realistic evolution of a cracked windshield during impact which may affect the head injury. The strain rate dependency of the PVB interlayer material is also considered in this model. Accordingly, MAT 123 "MAT_PIECEWISE_LINEAR_ 
TABle 3: Parameter settings of polyvinyl butyral laminated glass mode.

\begin{tabular}{|c|c|c|c|c|}
\hline Description & Variable & Outer glass & Inner glass & PVB \\
\hline Mass density & Rho $\left(\mathrm{kg} / \mathrm{m}^{3}\right)$ & 2500 & 2500 & 200 \\
\hline Poisson's ratio for glass & PRG & 0.23 & 0.23 & - \\
\hline Young's modulus for glass & $E_{\mathrm{g}}(\mathrm{GPa})$ & 100 & 68 & - \\
\hline Yield stress for glass & SYG (MPa) & 110 & 16 & - \\
\hline Plastic hardening modulus for glass & ETG (GPa) & 50 & 60 & - \\
\hline Plastic strain at failure for glass & EFG & 0.0004 & 0.00024 & - \\
\hline Young's modulus for polymer & $E_{\mathrm{p}}(\mathrm{MPa})$ & - & - & 280 \\
\hline Poisson's ratio for polymer & PRP & - & - & 0.495 \\
\hline Load curve ID defining effective stress versus effective plastic strain & LCSS & - & - & $1360 / \mathrm{s}$ \\
\hline
\end{tabular}

PLASTICITY," a linear elastic model of LS-DYNA material database, is selected to characterize the material characteristics of PVB and glass during dynamic impact simulations. The parameter settings are summarized in Table 3. During the head-to-windshield impact, the lower glass bears the tensile stress and fails first, while the upper glass bears the compression force and fails accordingly. Thus, the mechanical properties of the upper and lower glass are comprehensively determined by an extensive numerical evaluation referring to all dynamic compression and tensile test curves at different strain rates [33]. The upper glass plastic failure strain (0.0004) and the lower glass plastic failure strain (0.00024) are determined by an extensive numerical assessment based on compressive and tensile experimental data at different strain rates, respectively. According to a previous windshield test and a simulation study, the glass plastic failure strain ranges from 0.0001 to 0.001 [33-37]. Thus, the difference of properties between the upper glass layer and lower glass layer in this study is reasonable. In addition, the boundary condition of the windshield is fully constrained, and the relative impact speed and position between the head and the vehicle of MADYMO output are employed as the input speed [17] (both linear and angular velocity with different $x, y$, and $z$ components) of the FE head model in this paper. The contact type between the FE head and windshield models is set as "CONTACT_AUTOMATIC_ SURFACE_TO_SURFACE” algorithm with a friction coefficient of 0.1 [26]. Yu et al. [32] have validated that the FE windshield models were devised to provide a highly realistic cracking morphology with an enhanced impact response for the laminated windshield compared to the experimental tests. In addition, the windshield deflection and head form impactor acceleration profiles are much more realistic than those obtained in previous studies.

2.6. Injury Evaluation Index. Cerebral contusion and laceration of the brain, that is, coup and contrecoup contusions, belonging to traumatic brain injury, can be the result of a direct impact to the head $[38,39]$. Important brain parameters, such as coup pressure $P_{\mathrm{C}}$, contrecoup pressure $P_{\mathrm{CC}}$, von Mises stress $\sigma_{\mathrm{VM}}$, and maximum shear stress $\tau$, obtained from FE simulation have strong correlations with the risk of
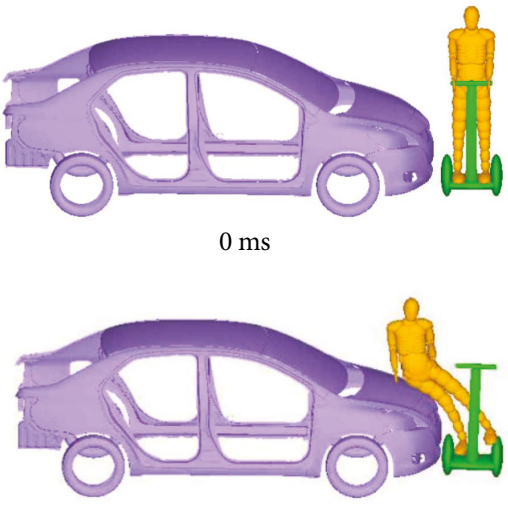

$100 \mathrm{~ms}$

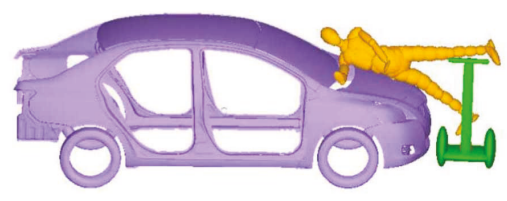

$200 \mathrm{~ms}$

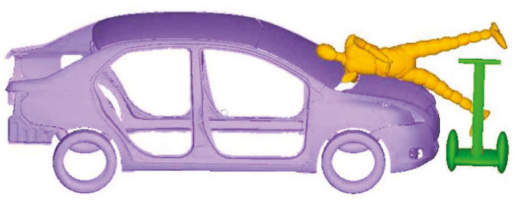

$226 \mathrm{~ms}$

FIGURE 2: Vehicle-ESS impact processes under vehicle impact speed of $7 \mathrm{~m} / \mathrm{s}$.

AIS 3+ brain injuries [9]. The reference values of stresses or pressures in the current study are derived from Yao et al. [9], that is, $P_{\mathrm{C}}, P_{\mathrm{CC}}, \sigma_{\mathrm{VM}}$, and $\tau$ are $256,-152,14.8$, and $7.9 \mathrm{kPa}$, respectively.

\section{Results and Discussion}

Take one numerical simulation for example. Figure 2 shows the impact process of vehicle doublewheel ESS accident 


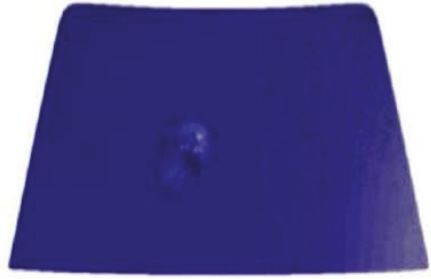

$0 \mathrm{~ms}$

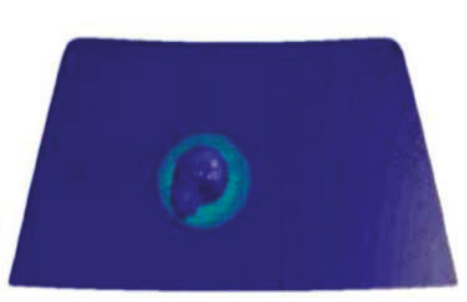

$4 \mathrm{~ms}$

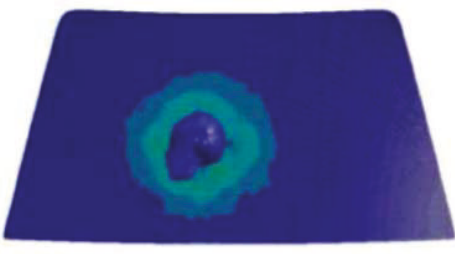

$6 \mathrm{~ms}$

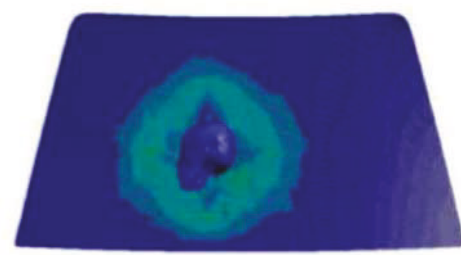

$10 \mathrm{~ms}$

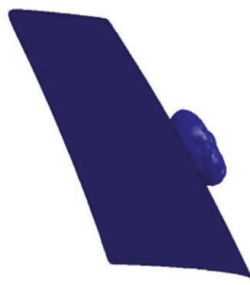

(a)

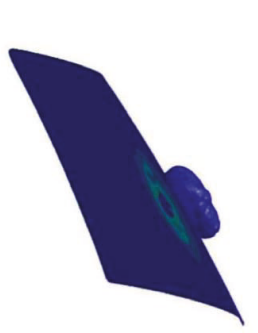

(b)

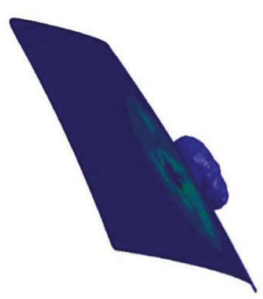

(c)

Fringe levels

$1.327 e+02$

$1.195 e+02$

$1.062 e+02$

$9.291 e+01$

$7.963 e+01$

$6.636 e+01$

$5.309 e+01$

$3.982 e+01$

$2.654 e+01$

$1.327 e+01$

$0.000 e+00$

Fringe levels

$1.327 e+02$

$1.195 e+02$

$1.062 e+02$

$9.291 e+01$

$7.963 e+01$

$6.636 e+01$

$5.309 e+01$

$3.982 e+01$

$2.654 e+01$

$1.327 e+01$

$0.000 e+00$

Fringe levels

$1.327 e+02$

$1.195 e+02$

$1.062 e+02$

$9.291 e+01$

$7.963 e+01$

$6.636 e+01$

$5.309 e+01$

$3.982 e+01$

$2.654 e+01$

$1.327 e+01$

$0.000 e+00$

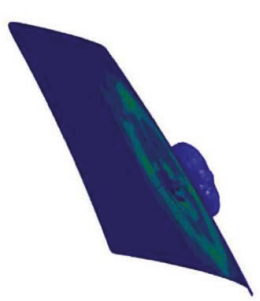

Fringe levels

$1.327 e+02$

$1.195 e+02$

$1.062 e+02$

$9.291 e+01$

$7.963 e+01$

$6.636 e+01$

$5.309 e+01$

$3.982 e+01$

$2.654 e+01$

$1.327 e+01$

$0.000 e+00$

(d)

Figure 3: Variations in the von Mises stress of the windshield under vehicle impact speed of $7 \mathrm{~m} / \mathrm{s}$. 

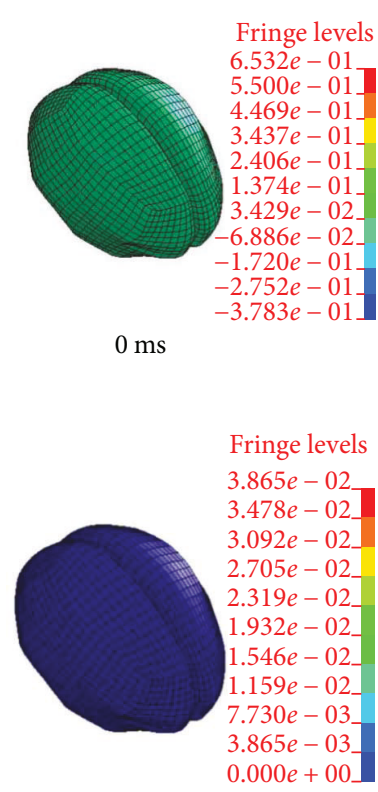

$0 \mathrm{~ms}$

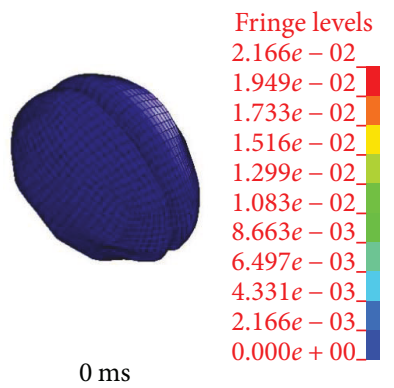

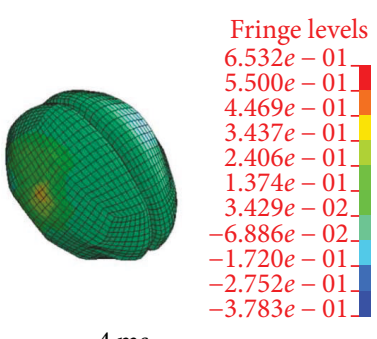

$4 \mathrm{~ms}$

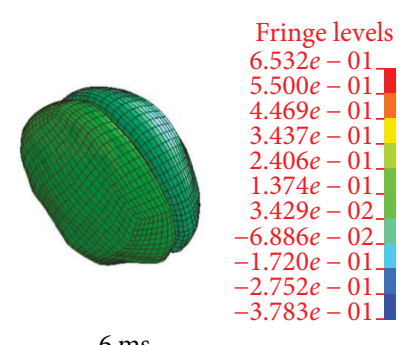

$6 \mathrm{~ms}$

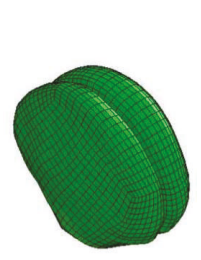

$10 \mathrm{~ms}$
Fringe levels $6.532 e-01$ $5.500 e-01]$ $4.469 e-01]$ $3.437 e-01$ $2.406 e-01]$ $1.374 e-01$ $3.429 e-02$ $3.429 e-02$ $-6.886 e-02$ $-1.720 e-01$ $-2.752 e-01-$

(a) Pressure variations of the brain

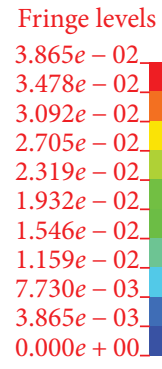

$4 \mathrm{~ms}$

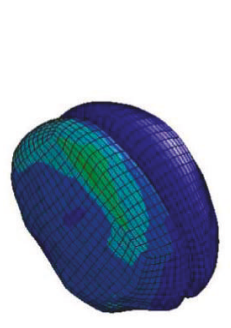

$6 \mathrm{~ms}$

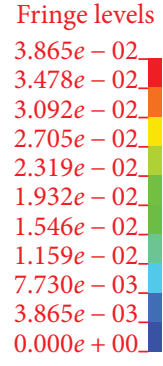

$0.000 e+00$

(b) von Mises stress variations of the brain

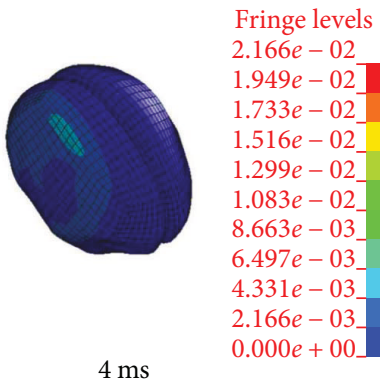

Fringe levels $2.166 e-02$ $1.949 e-02]$ $1.733 e-02$ $1.516 e-02$ $1.299 e-02$ $8.663 e-03$ $6.497 e-03$ $4.331 e-03$ $2.166 e-03$ $0.000 e+00$ $1.083 e-02$ (c) Shear stress variations of the brain

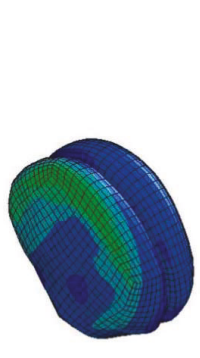

Fringe levels $3.865 e-02$ $3.478 e-02]$ $3.092 e-02$ $2.705 e-02$ $2.319 e-02$ $1.932 e-02$ $1.546 e-02$ $1.159 e-02$ $7.730 e-03$ $3.865 e-03$ $0.000 e+00$

$10 \mathrm{~ms}$

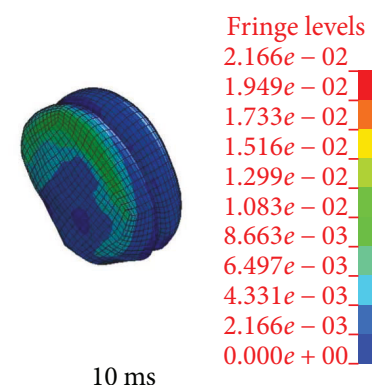

$10 \mathrm{~ms}$

FIGURE 4: Variations in the pressure and stress of the doublewheel ESS rider's cerebrum under vehicle impact speed of $7 \mathrm{~m} / \mathrm{s}$.

under impact speed of $V_{\mathrm{C}}=7 \mathrm{~m} / \mathrm{s}$. It can be observed that the ESS rider fell onto the bonnet after being hit by the vehicle, then, head-windshield contact occurred at $226 \mathrm{~ms}$. The cerebrum of an ESS rider suffers sustained pressures and stresses during head-windshield impact. Figure 3 shows the von Mises stress variations in the windshield. Figures 4(a)-4(c) show the pressure and stress variations in the doublewheel ESS rider's cerebrum.

The pressure quickly appears and diffuses in the collision half-side of the cerebrum when the initial head-windshield contact occurs. The cerebrum presents an obvious large deformation at $6 \mathrm{~ms}$, and the pressure has diffused to the whole brain region. At the last stage demonstrated in Figure 4, the cerebrum pressure increases continuously, and the deformation of the cerebrum reaches an extremum. A concentration of pressure can be observed on the collision side of the cerebrum shortly after the stress wave transmitted from the scalp to the skull and further through CSF to the cerebrum. Then, the stress has diffused to almost half of the cerebrum at $6 \mathrm{~ms}$. At the next stage, that is, at $10 \mathrm{~ms}$, the equivalent effective stress has diffused to the other side and reaches a maximum value $(38.6 \mathrm{kPa})$. The variation in the shear stress contour of the cerebrum is highly similar to the von Mises stress field distribution profile.

Vehicle impact speed is widely accepted as the leading factor $[5,40]$ for the severity of VRU head injuries during vehicular accidents. Therefore, a study of vehicle speed effect on brain injury was carried out. In the setting of MADYMO simulations, baseline vehicle ESS accident scenario (see Figure 1(a)) was employed. Six vehicle speeds $\left(V_{\mathrm{C}}=5,7,9,11,13\right.$, and $\left.15 \mathrm{~m} / \mathrm{s}\right)$ are considered to investigate the speed effect on the severity of ESS riders' head injuries caused by windshield collision. The boundary conditions of head-windshield impact were captured and accordingly employed to FE models. The relationships between $V_{\mathrm{C}}$ and $P_{\mathrm{C}}, P_{\mathrm{CC}}, \sigma_{\mathrm{VM}}$, and $\tau$ of ESS riders are illustrated in Figures 5(a) and 5(b), respectively.

Changes in the ESS moving speed $\left(V_{\mathrm{E}}\right)$ can lead to a change in the ESS riders' postimpact posture, thus affecting the severity of head-brain injuries. Similarly, a relative study was carried out to investigate ESS speed effect on brain injury. Vehicle ESS accident scenario was set as the baseline as shown in Figure 1(a). In addition, moving speeds were added in ESS and human models. Four ESS 


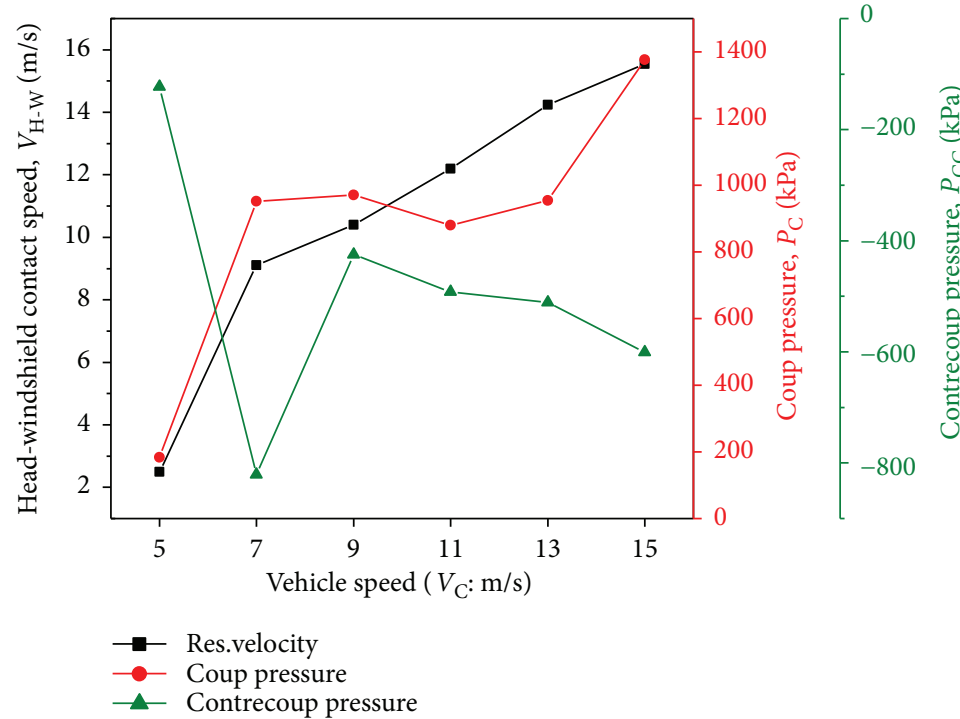

(a) Relation of vehicle speed and brain injury indices (coup pressure and

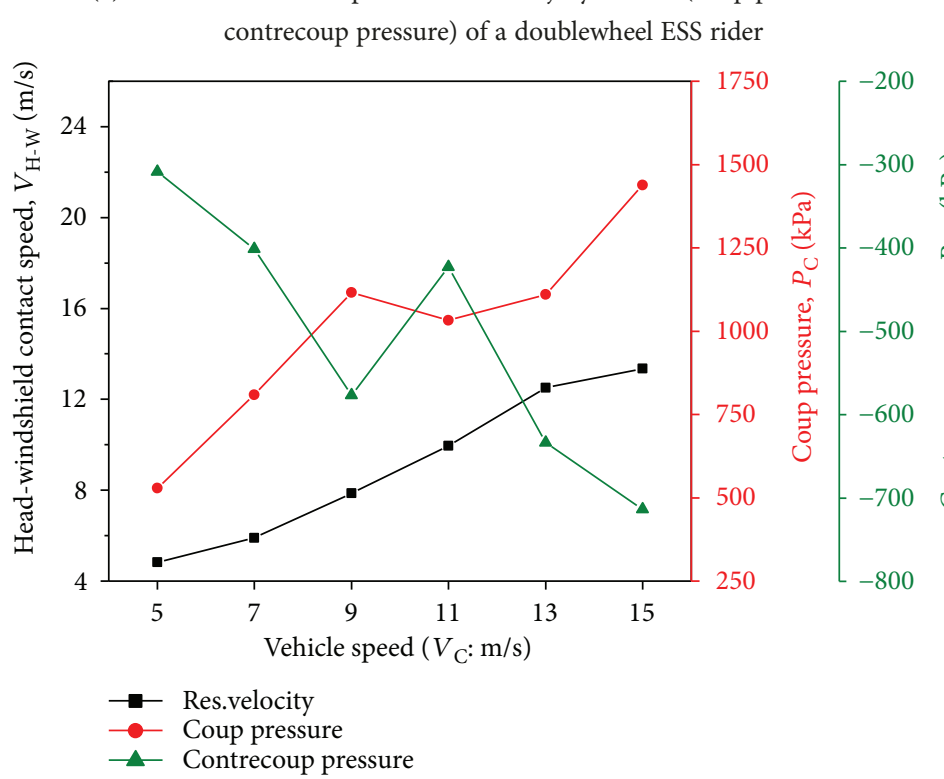

(c) Relation of vehicle speed and brain injury indices (coup pressure and contrecoup pressure) of a solowheel ESS rider

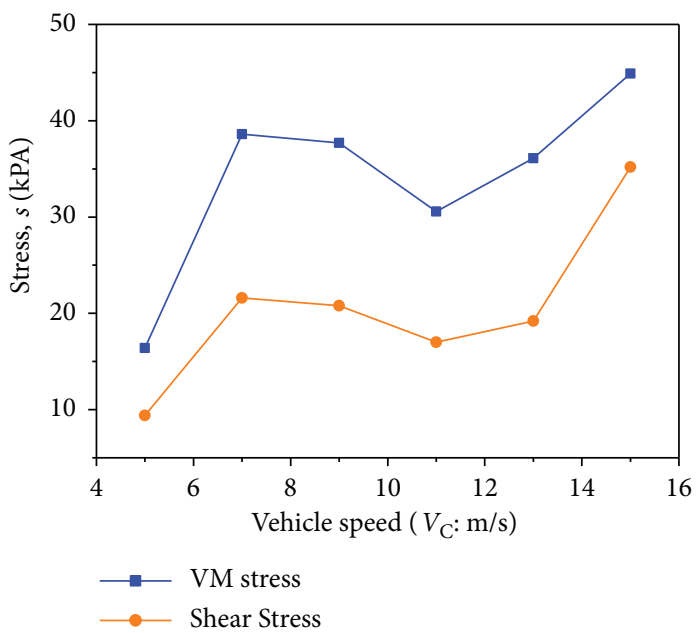

(b) Relation of vehicle speed and brain injury indices (von Mises stress and shear stress) of a doublewheel ESS rider

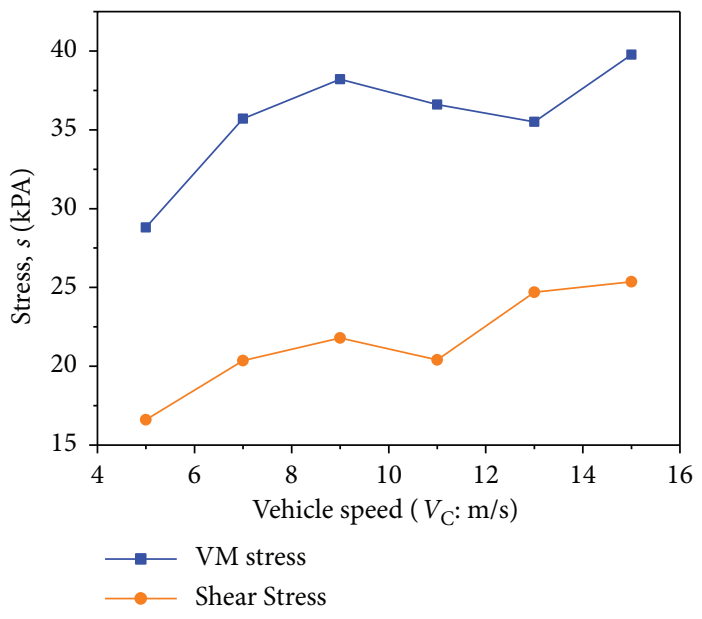

(d) Relation of vehicle speed and brain injury indices (von Mises stress and shear stress) of a solowheel ESS rider

Figure 5: Relation of vehicle speed and brain injury index of ESS riders at side impact baseline cases.

moving speeds $\left(V_{E}=0,1,2\right.$, and $\left.3 \mathrm{~m} / \mathrm{s}\right)$ are chosen as the input parameters to investigate the effect of ESS moving speed on brain injury at $V_{\mathrm{C}}=10 \mathrm{~m} / \mathrm{s}$ during head-windshield impact. The relationships between $V_{\mathrm{E}}$ and $P_{\mathrm{C}}, P_{\mathrm{CC}}, \sigma_{\mathrm{VM}}$, and $\tau$ of doublewheel and solowheel ESS riders are presented in Figures 6(a) and 6(b), respectively.

3.1. Effect of Vehicle Speed on Brain Injury. Figure 5 shows the relative speed between the head and the windshield, that is, $V_{\mathrm{H}-\mathrm{W}}$ increases with $V_{\mathrm{C}}$. In addition, $P_{\mathrm{C}}, P_{\mathrm{CC}}$, $\sigma_{\mathrm{VM}}$, and $\tau$ also generally have positive correlations with $V_{\mathrm{C}}$. As shown in Figures 5(a) and 5(b), there is a sharp increase of $V_{\mathrm{H}-\mathrm{W}}$ from $V_{\mathrm{C}}=5 \mathrm{~m} / \mathrm{s}$ to $7 \mathrm{~m} / \mathrm{s}$, which could explain the high absolute value of contrecoup pressure as well as other brain injury indices. In addition, as LSPrePost of FE simulations show, when the head impacts the windshield, the centralized pressure on the cerebrum moves relatively faster from the impact side to the offside in the two cases, resulting in the high absolute values of contrecoup pressure. By examining the MADYMO output animations and the collision times (Table 4) of headwindshield contacts, there is a big head-windshield impact time difference $(71 \mathrm{~ms})$ between solowheel cases with $V_{\mathrm{C}}=5 \mathrm{~m} / \mathrm{s}$ and $7 \mathrm{~m} / \mathrm{s}$, which makes a relatively large speed gap between the two vehicle-windshield contacts. The headwindshield contact points (as shown in Figure 7) may also change with the impact speed. For instance, the impact points are in the lower zone of the windshield when 


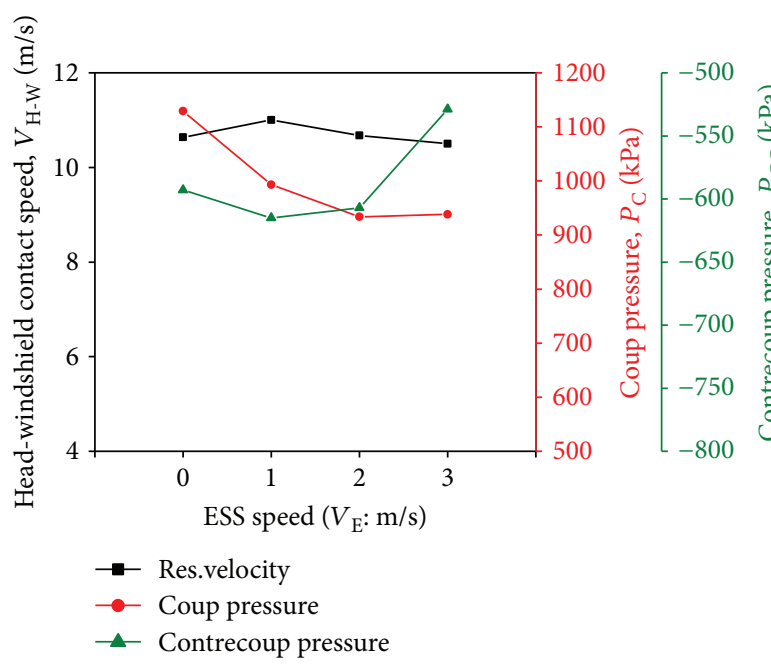

(a) Relation of ESS moving speeds and brain injury indices (coup pressure and contrecoup pressure) of a doublewheel ESS rider with an impact speed of $10 \mathrm{~m} / \mathrm{s}$

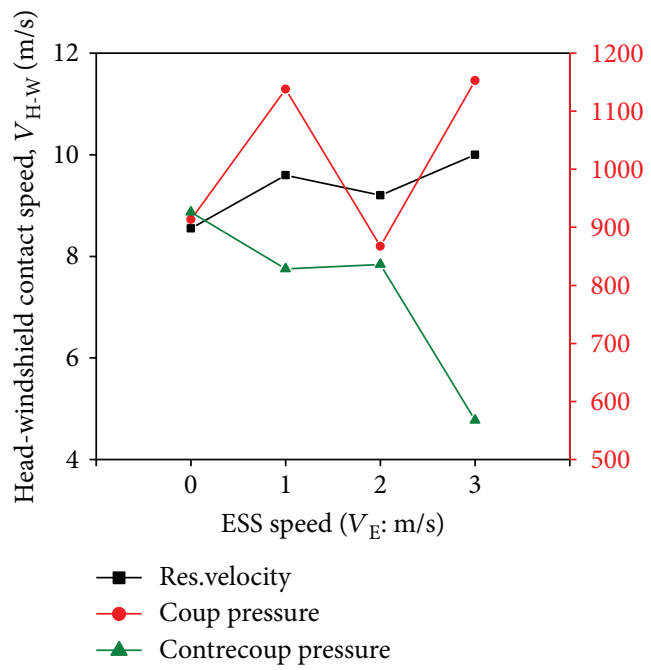

(c) Relation of ESS moving speeds and brain injury indices (coup pressure and contrecoup pressure) of a solowheel ESS rider with an impact speed of $10 \mathrm{~m} / \mathrm{s}$

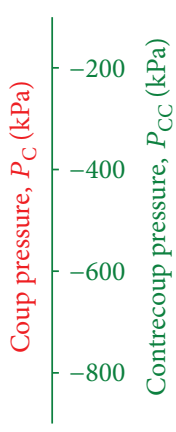

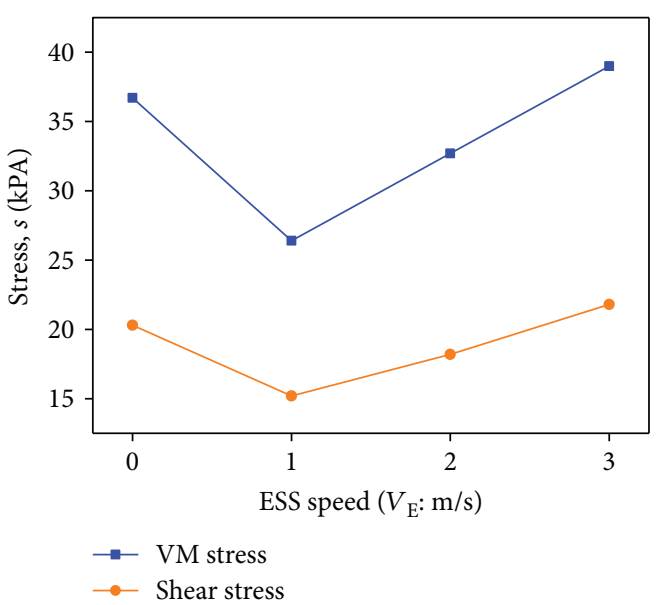

(b) Relation of ESS moving speeds and brain injury indices (von Mises stress and shear stress) of a doublewheel ESS rider with an impact speed of $10 \mathrm{~m} / \mathrm{s}$

(d) Relation of ESS moving speeds and brain injury indices (von Mises stress and shear stress) of a solowheel ESS rider with an impact speed of $10 \mathrm{~m} / \mathrm{s}$

FIGURE 6: Relation of ESS moving speeds and brain injury indices of ESS riders under the impact speed of $10 \mathrm{~m} / \mathrm{s}$.

TABle 4: Collision times of head-windshield contacts at different vehicle impact speed conditions.

\begin{tabular}{lcc}
\hline $\begin{array}{l}\text { Impact } \\
\text { condition }\end{array}$ & $\begin{array}{c}\text { Time of head-windshield } \\
\text { contact (doublewheel) }\end{array}$ & $\begin{array}{c}\text { Time of head-windshield } \\
\text { contact (solowheel) }\end{array}$ \\
\hline$V_{\mathrm{C}}=5 \mathrm{~m} / \mathrm{s}$ & $295 \mathrm{~ms}$ & $376 \mathrm{~ms}$ \\
$V_{\mathrm{C}}=7 \mathrm{~m} / \mathrm{s}$ & $224 \mathrm{~ms}$ & $265 \mathrm{~ms}$ \\
$V_{\mathrm{C}}=9 \mathrm{~m} / \mathrm{s}$ & $182 \mathrm{~ms}$ & $210 \mathrm{~ms}$ \\
$V_{\mathrm{C}}=11 \mathrm{~m} / \mathrm{s}$ & $155 \mathrm{~ms}$ & $167 \mathrm{~ms}$ \\
$V_{\mathrm{C}}=13 \mathrm{~m} / \mathrm{s}$ & $136 \mathrm{~ms}$ & $139 \mathrm{~ms}$ \\
$V_{\mathrm{C}}=15 \mathrm{~m} / \mathrm{s}$ & $124 \mathrm{~ms}$ & $129 \mathrm{~ms}$ \\
\hline
\end{tabular}

$V_{\mathrm{C}}=5 \mathrm{~m} / \mathrm{s}$ moves to a much higher position at $V_{\mathrm{C}}=15 \mathrm{~m} / \mathrm{s}$. It indicates that $V_{\mathrm{H}-\mathrm{W}}$ and head contact location on windshield influences the severity of brain injuries. Therefore, these two parameters were discussed in detail in the following sections of this study.

3.2. Effect of ESS Moving Speed on Brain Injury. As shown in Figure 6, brain injury indices are relatively lower at $V_{\mathrm{E}}=0 \mathrm{~m} / \mathrm{s}$, and $P_{\mathrm{C}}, P_{\mathrm{CC}}, \sigma_{\mathrm{VM}}$, and $\tau$ show no obvious correlations with $V_{\mathrm{E}}$. However, $V_{\mathrm{E}}$ and brain injury indices are generally correlated in solowheel cases except the suddenly increased coup pressure when $V_{\mathrm{E}}=1 \mathrm{~m} / \mathrm{s}$. The MADYMO output results show that locations of head and windshield impact are also strongly influenced by ESS moving speed. By examining the FE head-windshield impact simulation, when $V_{\mathrm{E}}=1 \mathrm{~m} / \mathrm{s}$, the head has a lager deformation compared to the situation of ESS and the speed is zero, which may take the responsibility to the high value of coup pressure. Moreover, it can be speculated that with the increase 


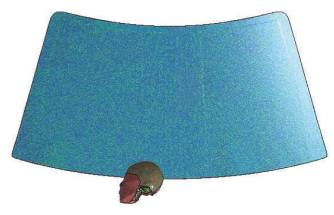

Doublewheel $\left(V_{\mathrm{C}}=5 \mathrm{~m} / \mathrm{s}\right)$

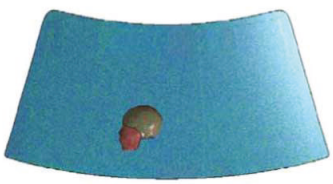

Doublewheel $\left(V_{\mathrm{C}}=7 \mathrm{~m} / \mathrm{s}\right)$

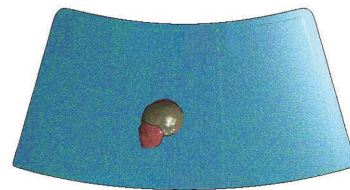

Doublewheel $\left(V_{\mathrm{C}}=9 \mathrm{~m} / \mathrm{s}\right)$

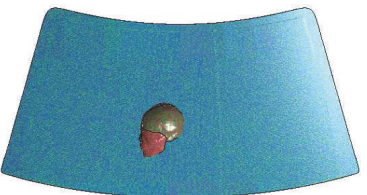

Doublewheel $\left(V_{\mathrm{C}}=11 \mathrm{~m} / \mathrm{s}\right)$

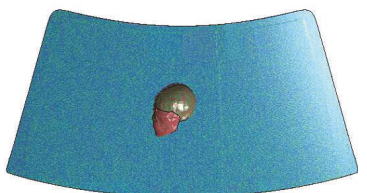

Doublewheel $\left(V_{\mathrm{C}}=13 \mathrm{~m} / \mathrm{s}\right)$

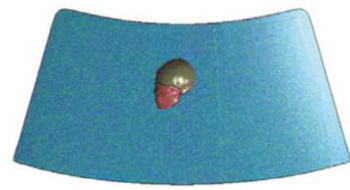

Doublewheel $\left(V_{\mathrm{C}}=15 \mathrm{~m} / \mathrm{s}\right)$

(a)

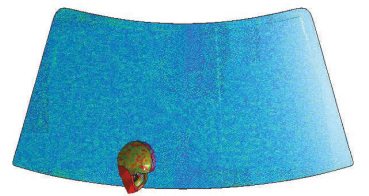

Solowheel $\left(V_{\mathrm{C}}=5 \mathrm{~m} / \mathrm{s}\right)$

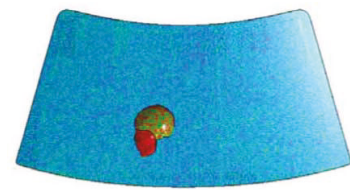

Solowheel $\left(V_{\mathrm{C}}=7 \mathrm{~m} / \mathrm{s}\right)$

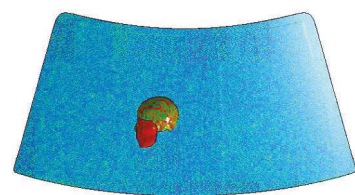

Solowheel $\left(V_{\mathrm{C}}=9 \mathrm{~m} / \mathrm{s}\right)$

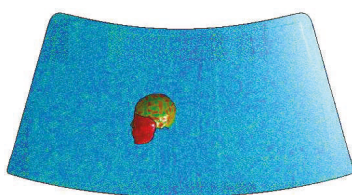

Solowheel $\left(V_{\mathrm{C}}=11 \mathrm{~m} / \mathrm{s}\right)$

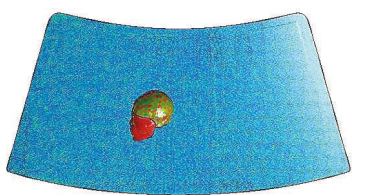

Solowheel $\left(V_{\mathrm{C}}=13 \mathrm{~m} / \mathrm{s}\right)$

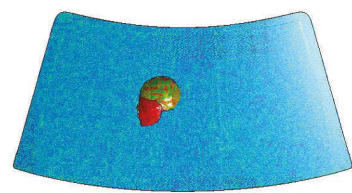

Solowheel $\left(V_{\mathrm{C}}=15 \mathrm{~m} / \mathrm{s}\right)$

(b)

Figure 7: Head collision points on windshield under different vehicle impact speeds.

of $V_{\mathrm{E}}, V_{\mathrm{H}-\mathrm{W}}$ changes not much (within a fluctuation range of $2 \mathrm{~m} / \mathrm{s}$, as shown in Figure 6) while the impact locations on the windshield can vary widely (see Figure 8). It strengthens the importance to investigate the effect of the impact location of the windshield on the ESS rider's brain injury.

3.3. Effect of Vehicle ESS Impact Angle on Brain Injury. A previous study showed that the relative angle $(\theta)$ between the vehicle speed orientation and the ESS rider's facing direction has a major impact on the head contact regions and $\mathrm{HIC}_{15}$ values, as demonstrated in a previous study [5]. A series of parametric studies are performed to evaluate the influence of the impact angle $\theta$ when $V_{\mathrm{C}}=10 \mathrm{~m} / \mathrm{s}$. The seven impact angles $(\theta=0, \pi / 6, \pi / 3, \pi / 2,2 \pi / 3,5 \pi / 6$, and $\pi)$ are illustrated in Figure 9.

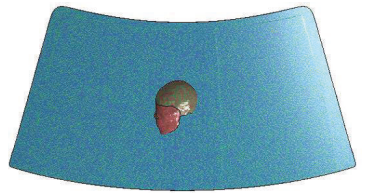

Doublewheel $\left(V_{\mathrm{E}}=0 \mathrm{~m} / \mathrm{s}\right)$

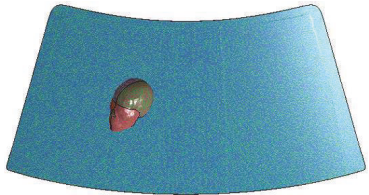

Doublewheel $\left(V_{\mathrm{E}}=1 \mathrm{~m} / \mathrm{s}\right)$

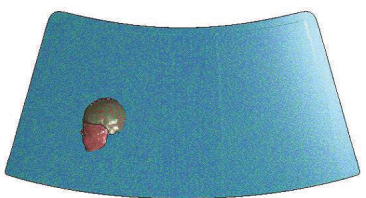

Doublewheel $\left(V_{\mathrm{E}}=2 \mathrm{~m} / \mathrm{s}\right)$

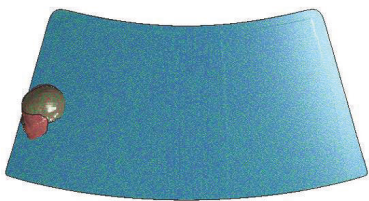

Doublewheel $\left(V_{\mathrm{E}}=3 \mathrm{~m} / \mathrm{s}\right)$

(a)

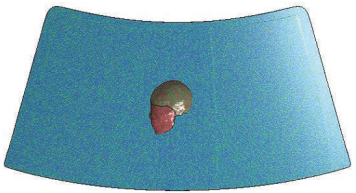

Doublewheel $\left(V_{\mathrm{E}}=0 \mathrm{~m} / \mathrm{s}\right)$

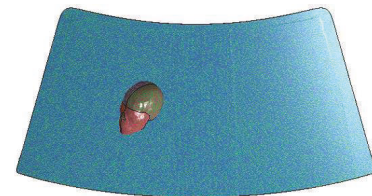

Doublewheel $\left(V_{\mathrm{E}}=1 \mathrm{~m} / \mathrm{s}\right)$

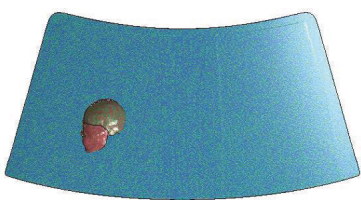

Doublewheel $\left(V_{\mathrm{E}}=2 \mathrm{~m} / \mathrm{s}\right)$

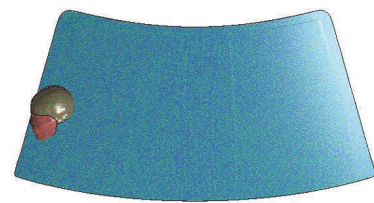

Doublewheel $\left(V_{\mathrm{E}}=3 \mathrm{~m} / \mathrm{s}\right)$

(b)
FIgURE 8: Head collision points on windshield under different ESS moving speeds.

The relations of $\theta$ and $P_{\mathrm{C}}, P_{\mathrm{CC}}, \sigma_{\mathrm{VM}}$, and $\tau$ are presented in Figure 10. $V_{\mathrm{H}-\mathrm{W}}$ does not remarkably vary in most doublewheel cases, except at $\theta=5 \pi / 6$ if the impact speed between the ESS rider and vehicle is constant. The variation in the brain injury indices is consistent with that of $V_{\mathrm{H}-\mathrm{W}}$. However, in solowheel cases, $V_{\mathrm{H}-\mathrm{W}}$ is more sensitive to the changes in $\theta$, and no obvious correlation between $V_{\mathrm{H}-\mathrm{W}}$ and brain injury indices is found. The MADYMO output results show that the head contact location plays an important role in brain injury.

3.4. Effect of Head Impact Speed (Linear Velocity) on Brain Injury. Previous studies showed that head impact speed is an important factor that influences VRU head-brain injuries during impact [41]. $V_{\mathrm{H}-\mathrm{W}}$ is highly dependent on the vehicle impact speed $V_{\mathrm{C}}$. Consequently, higher $V_{\mathrm{C}}$ produces more serious brain injuries caused by windshield contact. $V_{\mathrm{H}-\mathrm{W}}$ is first parametrically analyzed in this section. A typical impact scenario of an ESS rider's head-windshield contact is employed (shown in Figure 1(f)). $V_{\mathrm{H}-\mathrm{W}}$ varies from $3 \mathrm{~m} / \mathrm{s}$ to $9 \mathrm{~m} / \mathrm{s}$ with a vertical orientation. Figure 11 shows the relationship between $V_{\mathrm{H}-\mathrm{W}}$ and $P_{\mathrm{C}}, P_{\mathrm{CC}}, \sigma_{\mathrm{VM}}$, and $\tau$. The brain injury indices are positively correlated with $V_{\mathrm{H}-\mathrm{W}}$, indicating that the risk of suffering more serious brain injuries increases with impact speed.

3.5. Effect of Head Impact Speed (Angular Velocity) on Brain Injury. According to the MADYMO outputs, besides the 


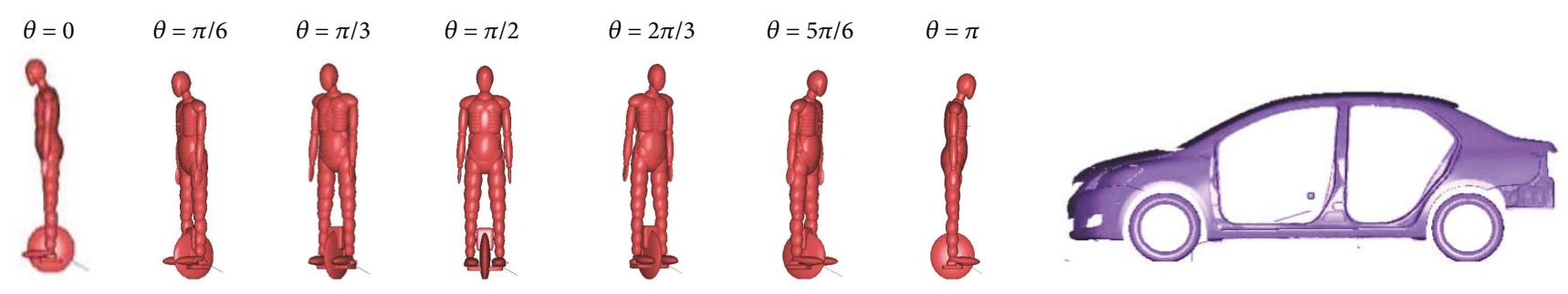

FIgURE 9: Description of different vehicle ESS impact angles under the impact speed of $10 \mathrm{~m} / \mathrm{s}$.

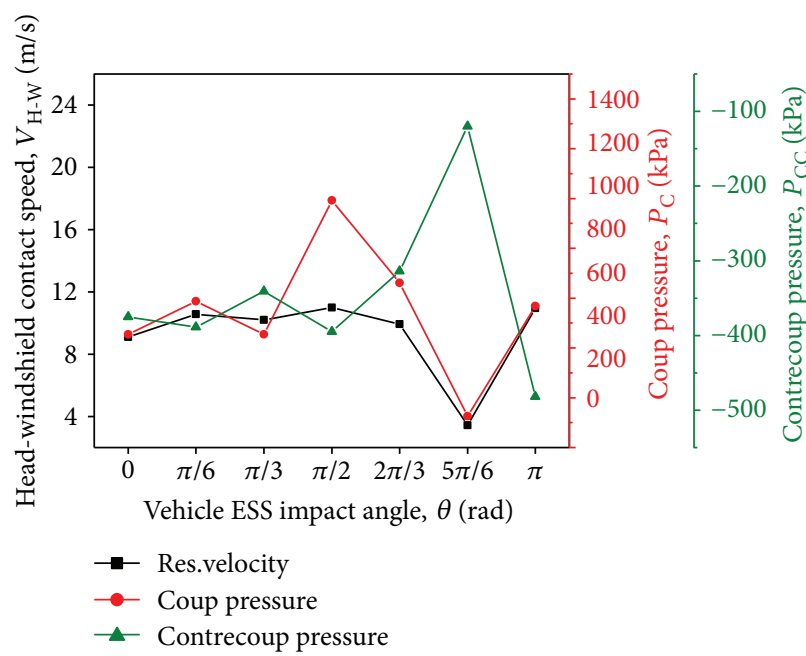

(a) Relation of vehicle ESS impact angles and brain injury indices (coup pressure and contrecoup pressure) of doublewheel ESS riders under the impact speed of $10 \mathrm{~m} / \mathrm{s}$

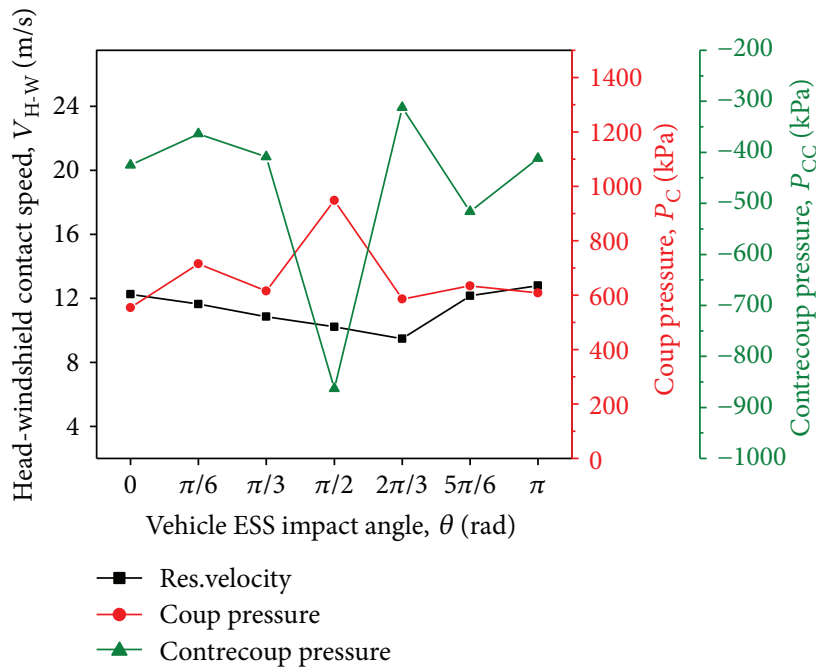

(c) Relation of vehicle ESS impact angles and brain injury indices (coup pressure and contrecoup pressure) of solowheel ESS riders under the impact speed of $10 \mathrm{~m} / \mathrm{s}$

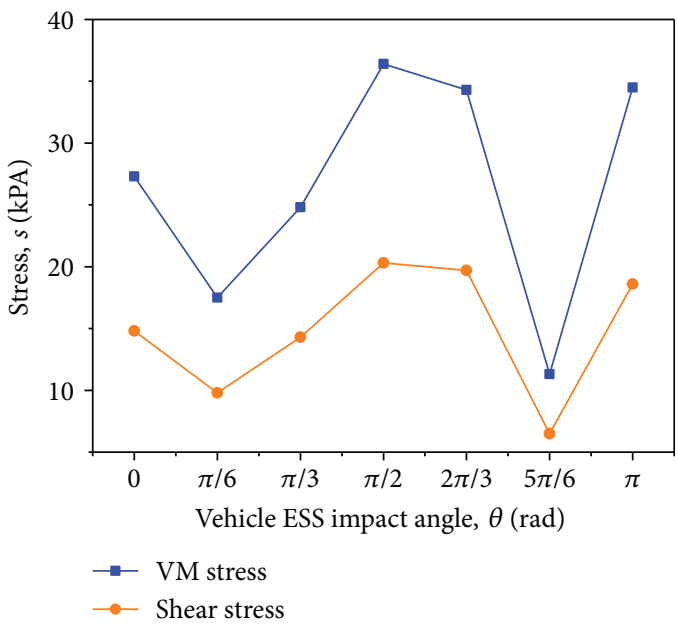

(b) Relation of vehicle ESS impact angles and brain injury indices (von Mises stress and shear stress) of doublewheel ESS riders under the impact speed of $10 \mathrm{~m} / \mathrm{s}$

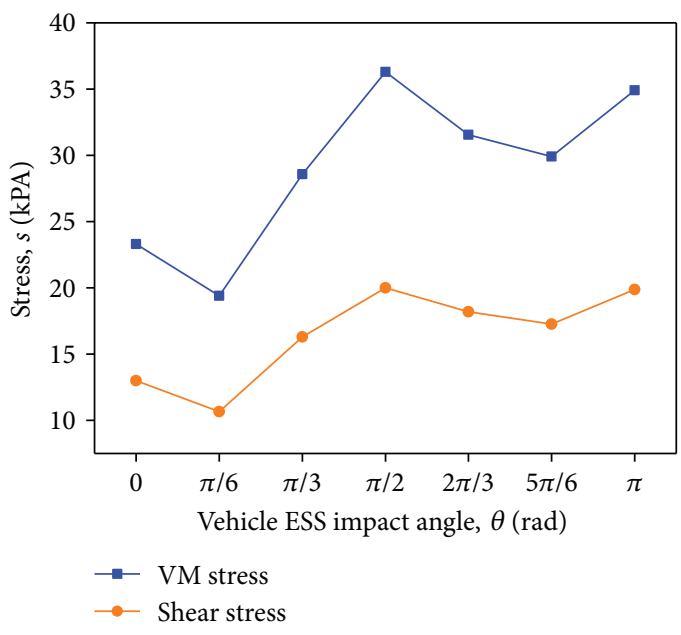

(d) Relation of vehicle ESS impact angles and brain injury indices (von Mises stress and shear stress) of solowheel ESS riders under the impact speed of $10 \mathrm{~m} / \mathrm{s}$

FIGURE 10: Relation of vehicle ESS impact angles and brain injury indices of ESS riders under the impact speed of $10 \mathrm{~m} / \mathrm{s}$.

linear velocity of the head, the angular velocity is also easy to be affected. Therefore, the effect of head impact angular velocity on brain injury is parametrically studied in this section. The impact scenario of head-windshield contact is in Figure 12(a) in which the angular velocity $\omega_{\mathrm{H}}$ varies from $20 \mathrm{rad} / \mathrm{s}$ to $60 \mathrm{rad} / \mathrm{s}$. The relationship between $\omega_{\mathrm{H}}$ and brain injury indices is illustrated in Figure 13. It can be observed that the values of $P_{\mathrm{C}}, P_{\mathrm{CC}}, \sigma_{\mathrm{VM}}$, and $\tau$ are positively correlated $\omega_{\mathrm{H}}$ but the influence is less compared with linear speed. 


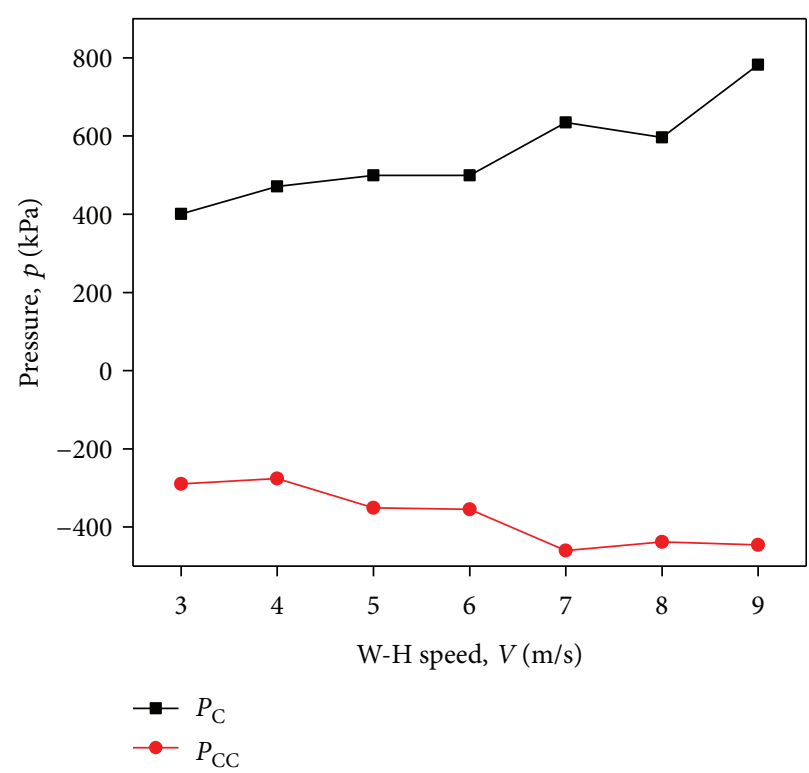

(a) Relation of head-windshield impact speeds and brain pressures of ESS riders

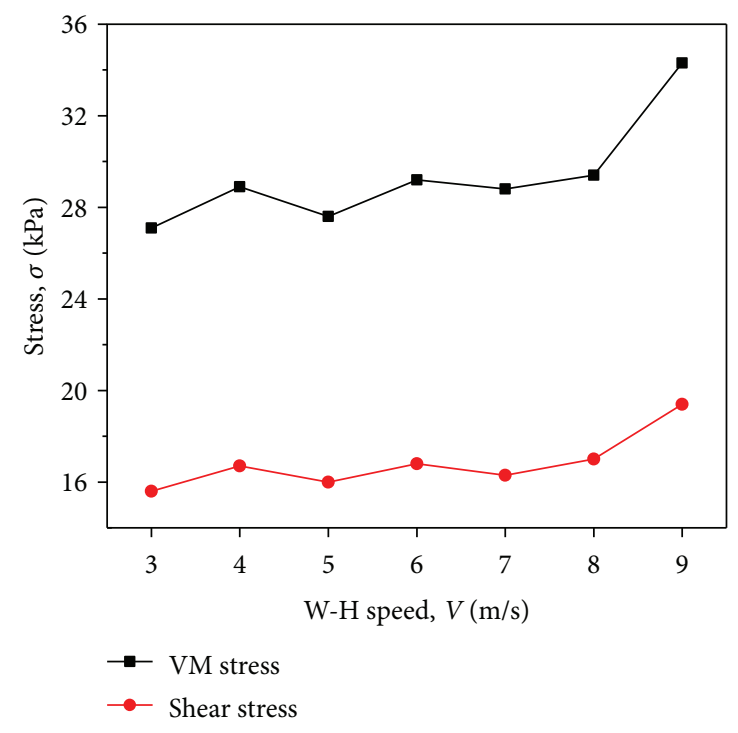

(b) Relation of head-windshield impact speeds and brain stresses of ESS riders

FIGURE 11: Relation of head-windshield impact speeds and brain injury indices of ESS riders under a typical impact scenario.

3.6. Effect of the Impact Location on the Windshield on Brain Injury. As mentioned in previous sections, further research of the impact location of windshield's effect on brain injury is warranted. Fifteen collision points on the outer surface of a windshield are evenly assigned (Figure 12(b)) to study the influence of these points on brain injury. In this parametric study, the orientation of $V_{\mathrm{H}-\mathrm{W}}$ is set as perpendicularly down with a speed of $10 \mathrm{~m} / \mathrm{s}$. Meanwhile, the relative altitude between the head and the windshield is illustrated in Figure 12(c). Brain injury indices obtained in each impact point case are listed in Table 5 . The results show that $P_{\mathrm{C}}$, $P_{\mathrm{CC}}, \sigma_{\mathrm{VM}}$, and $\tau$ are relatively high when ESS riders' head impacts the areas of $\mathrm{A} 1, \mathrm{~B} 3, \mathrm{~B} 5$, and $\mathrm{C} 5$. The average values of $P_{\mathrm{C}}, P_{\mathrm{CC}}, \sigma_{\mathrm{VM}}$, and $\tau$ are $772.42 \pm 93.4,-367 \pm 232.54$, $36.38 \pm 1.27$, and $19.82 \pm 0.94 \mathrm{kPa}$, respectively. These values indicate that the collision region of the windshield has a great influence over $P_{\mathrm{CC}}$ but slightly influences $P_{\mathrm{C}}, \sigma_{\mathrm{VM}}$, and $\tau$. Note that the surface of the windshield is convex rather than plane, changing the impact location on the windshield will alter the contact surface of the head model with the process of collision. In addition, boundary conditions of the windshield may also influence the biomechanical response of the brain.

\subsection{Effect of Head Impact Region on Brain Injury. MADYMO} output animations of a previous study (Section 3.3), which involves ESS rider's initial orientation effect on brain injury, showed the orientation of the head, that is, head impact region, which remarkably varies when the contact with windshield happened. In addition, the kinematic postures of ESS riders vary greatly with large uncertainties under diverse impact conditions [6]. Therefore, parametric studies are conducted to investigate the effect of head impact region on brain injury. The first case considered is when the ESS rider's head is facing toward the outer surface of the windshield, that is, $\theta_{\mathrm{H}-\mathrm{W}}=0$ (Figure $12(\mathrm{~d})$ ). Other head-windshield collision postures $\left(\theta_{\mathrm{H}-\mathrm{W}}=0, \pi / 6, \pi / 3, \pi / 2,2 \pi / 3,5 \pi / 6\right.$, and $\left.\pi\right)$ are adopted by rotating the $\mathrm{FE}$ head model around the vertical axis. A series of parametric studies are conducted based on different head impact regions at the same vertical headwindshield impact speed $\left(V_{\mathrm{H}-\mathrm{W}}=10 \mathrm{~m} / \mathrm{s}\right) . P_{\mathrm{C}}, P_{\mathrm{CC}}, \sigma_{\mathrm{VM}}$, and $\tau$ produced under different $\theta_{\mathrm{H}-\mathrm{W}}$; cases are summarized in Table 6. The head impact location remarkably influences the brain injuries. The average values of $P_{\mathrm{C}}, P_{\mathrm{CC}}, \sigma_{\mathrm{VM}}$, and $\tau$ are $606.43 \pm 100.24,-430.43 \pm 50.20,30.13 \pm 3.88$, and $16.93 \pm 2.27 \mathrm{kPa}$, respectively.

Then, the FE head model is rotated around the coronal axis to test another set of head-windshield collision angles, the intersection angle between human coronal section, and the tangent plane of the windshield as the impact posture for parametric study. The collision angles are selected based on the realistic situation (Figure 12(e)). Table 7 shows that the brain injury indices vary greatly with the change in head-windshield collision angles. For instance, $P_{\mathrm{C}}, P_{\mathrm{CC}}$, $\sigma_{\mathrm{VM}}$, and $\tau$ are relatively high at $\alpha_{\mathrm{H}-\mathrm{W}}=60^{\circ}$ and $\alpha_{\mathrm{H}-\mathrm{W}}=100^{\circ}$ but with low values in the case of $\beta_{\mathrm{H}-\mathrm{W}}=60^{\circ}$. The average values of $P_{\mathrm{C}}, P_{\mathrm{CC}}, \sigma_{\mathrm{VM}}$, and $\tau$ are $691.06 \pm 311.39$, $-596.28 \pm 325.27,31.32 \pm 4.82$, and $17.86 \pm 2.89 \mathrm{kPa}$, respectively. Note that the shape of the brain model is not absolutely symmetrical in all directions. Different contact surfaces of the head are bound to bring change in the values of pressures and stresses.

\section{Conclusion}

In this paper, the multirigid body human and FE vehicle models are coupled to simulate the potential crash accidents. The initial factors on ESS riders' brain injuries subjected to the windshield contact are examined by varying the vehicle impact speed and the ESS moving speed. The results show 


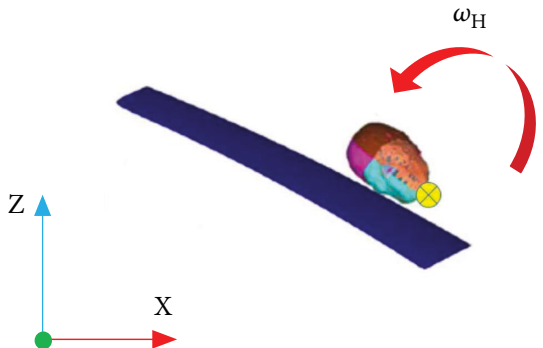

(a) Description of head-windshield collision postures, that is, the head is rotated with a $y$ axis which passes through the yellow point

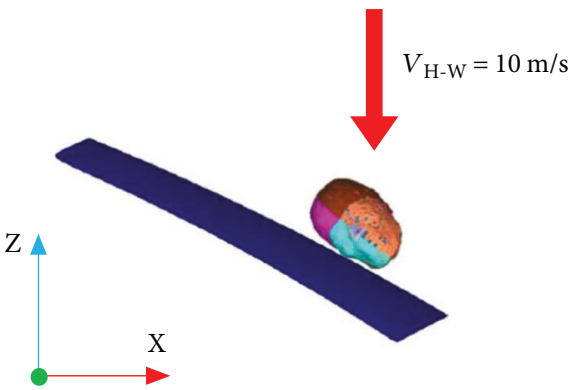

(c) Relative altitude between head and windshield in the parametric study of the effect of windshield impact location

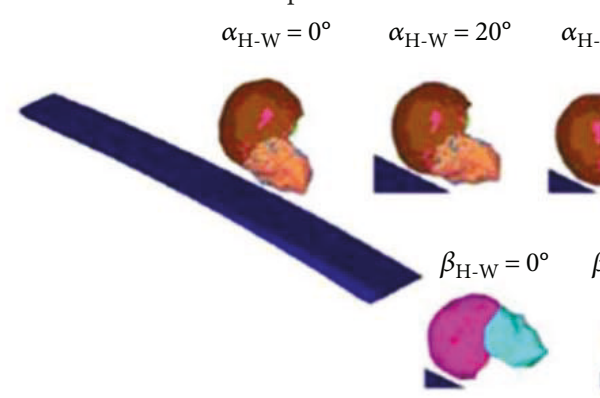

(e) Description of head-windshield collision postures, that is, the head is rotated with the coronal axis

Figure 12: Description of different head-windshield impact situations.

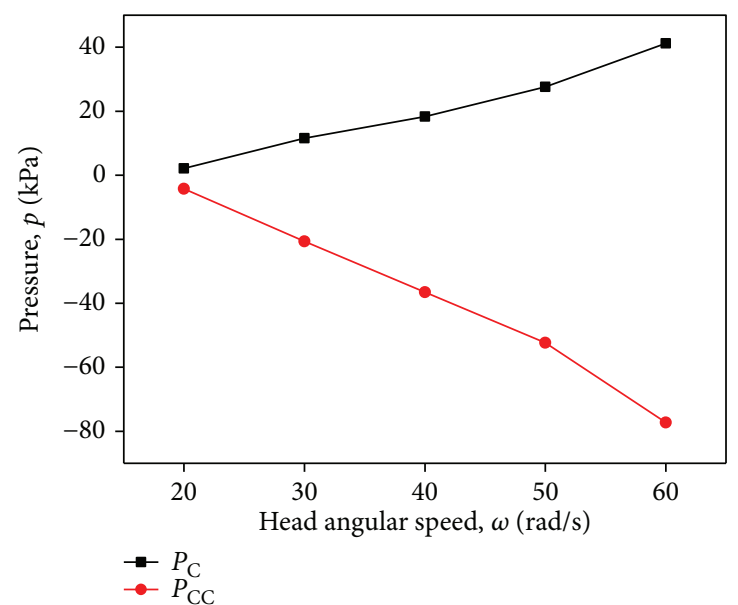

(a) Relation of head angular speed and brain pressures of ESS riders

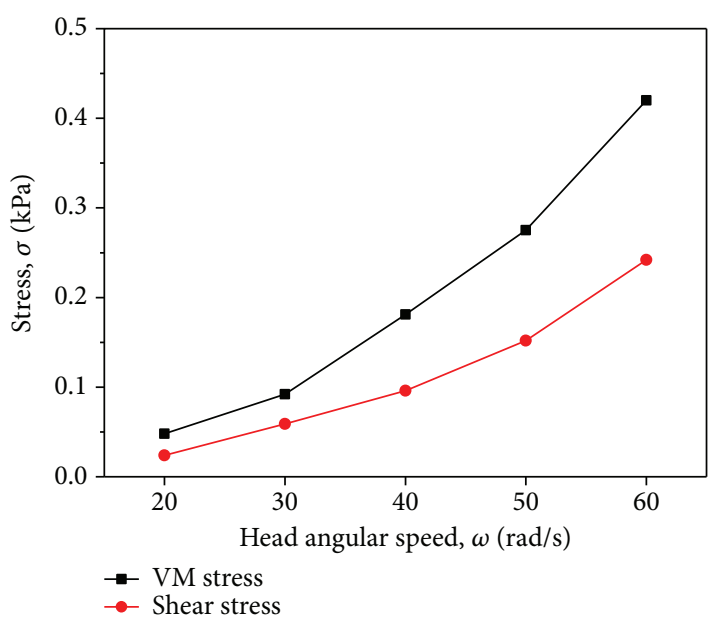

(b) Relation of head angular speed and brain stresses of ESS riders

FIGURE 13: Relation of head angular velocities and brain injury indices of ESS riders under a typical impact scenario. 
TABLE 5: Brain injury indices at each impact point of windshield under head-windshield impact speed of $10 \mathrm{~m} / \mathrm{s}$.

\begin{tabular}{lcccc}
\hline Impact point & $P_{\mathrm{C}}(\mathrm{kPa})$ & $P_{\mathrm{CC}}(\mathrm{kPa})$ & $\sigma_{\mathrm{VM}}(\mathrm{kPa})$ & $\tau(\mathrm{kPa})$ \\
\hline A1 & 755 & -297 & 34.7 & 18.8 \\
A2 & 767 & -558 & 36.3 & 19.4 \\
A3 & 721.7 & -407.7 & 36.5 & 19.7 \\
A4 & 772 & -355 & 37.6 & 20.7 \\
A5 & 737 & -426.5 & 37.17 & 20.6 \\
B1 & 711 & -550 & 33.5 & 18 \\
B2 & 691.9 & -546.6 & 36.4 & 19.5 \\
B3 & 1066 & -428 & 36.8 & 19.9 \\
B4 & 786 & -374 & 37.4 & 20.6 \\
B5 & 782 & 424.6 & 37.4 & 20.9 \\
C1 & 700 & -338 & 34.7 & 18.6 \\
C2 & 731 & -362 & 35.3 & 18.9 \\
C3 & 723.7 & -399 & 37 & 20.1 \\
C4 & 761 & -428.8 & 37.1 & 20.5 \\
C5 & 881 & -459 & 37.9 & 21.1 \\
\hline
\end{tabular}

TABLE 6: Brain injury indices for each head-windshield collision posture (head is rotated about the vertical axis) under headwindshield impact speed of $10 \mathrm{~m} / \mathrm{s}$.

\begin{tabular}{lcccc}
\hline$\theta_{\mathrm{H}-\mathrm{W}}(\mathrm{rad})$ & $P_{\mathrm{C}}(\mathrm{kPa})$ & $P_{\mathrm{CC}}(\mathrm{kPa})$ & $\sigma_{\mathrm{VM}}(\mathrm{kPa})$ & $\tau(\mathrm{kPa})$ \\
\hline 0 & 653 & -456 & 33.5 & 19 \\
$\pi / 6$ & 579 & -462 & 28.7 & 15.7 \\
$\pi / 3$ & 798 & -468 & 34 & 19.6 \\
$\pi / 2$ & 621 & -385 & 33.7 & 18.5 \\
$2 \pi / 3$ & 485 & -343 & 30.3 & 17.3 \\
$5 \pi / 6$ & 542 & -478 & 24 & 13.7 \\
$\pi$ & 567 & -421 & 26.7 & 14.7 \\
\hline
\end{tabular}

TABLE 7: Brain injury indices for each head-windshield collision posture (head is rotated about the coronal axis) under headwindshield impact speed of $10 \mathrm{~m} / \mathrm{s}$.

\begin{tabular}{lcccc}
\hline $\begin{array}{l}\text { Head-windshield } \\
\text { impact posture }\end{array}$ & $P_{\mathrm{C}}(\mathrm{kPa})$ & $P_{\mathrm{CC}}(\mathrm{kPa})$ & $\sigma_{\mathrm{VM}}(\mathrm{kPa})$ & $\tau(\mathrm{kPa})$ \\
\hline$\alpha_{\mathrm{H}-\mathrm{W}}=0^{\circ}$ & 653 & -456 & 33.5 & 19 \\
$\alpha_{\mathrm{H}-\mathrm{W}}=20^{\circ}$ & 530 & -370 & 35.3 & 19.9 \\
$\alpha_{\mathrm{H}-\mathrm{W}}=40^{\circ}$ & 683 & -677 & 33.2 & 19.1 \\
$\alpha_{\mathrm{H}-\mathrm{W}}=60^{\circ}$ & 1066 & -1031 & 35.1 & 20.2 \\
$\alpha_{\mathrm{H}-\mathrm{W}}=80^{\circ}$ & 618 & -626 & 38 & 22 \\
$\alpha_{\mathrm{H}-\mathrm{W}}=100^{\circ}$ & 1414 & -1292 & 34 & 19.7 \\
$\beta_{\mathrm{H}-\mathrm{W}}=0^{\circ}$ & 567 & -421 & 26.7 & 14.7 \\
$\beta_{\mathrm{H}-\mathrm{W}}=20^{\circ}$ & 460 & -330 & 26.7 & 15.3 \\
$\beta_{\mathrm{H}-\mathrm{W}}=40^{\circ}$ & 438.6 & -326.8 & 26.9 & 15.1 \\
$\beta_{\mathrm{H}-\mathrm{W}}=60^{\circ}$ & 481 & -433 & 23.8 & 13.6 \\
\hline
\end{tabular}

that the brain injury indices increase with head-windshield impact speed. The ESS moving speed also has an influence on the head-windshield contact. Injury indices are relatively large under high vehicle speed $(15 \mathrm{~m} / \mathrm{s})$ and ESS moving speed $(3 \mathrm{~m} / \mathrm{s})$ impact situations. However, no obvious correlations can be found between ESS moving speed and brain injury indices due to the joint action of relative headwindshield impact speed, impact location on the windshield, and head impact area. Series of designed parametric studies proved that the values of brain injury indices have positive correlations with both linear and angular velocities of the head. The results may remove a critical barrier for forensic analysis and accident reconstruction and may be used to guide vehicle/ESS safety designs.

It should be noticed that there are also limitations with this study. Firstly, we found there is no video resource of real-world vehicle ESS impact accident for reconstruction and comparison. Secondly, it saved us loads of hours by using MB pedestrian model and head model instead of whole-body model to analyze the head and brain injuries of ESS rides, but in the meantime, it may result in a slight difference in kinematics [42]. Thirdly, the reference values of stresses or pressures of the FE head model used in this study are not clear even though it does not affect the model and could be used comparing the injuries at different impact conditions. Fourthly, since there is a tiebreak contact interface between the skull and brain of the FE head model which may allow sliding with separation; then, the accuracy of the results may be influenced by this unphysical behavior. Last but not the least, we studied the vehicle speed, ESS speed, head-windshield impact speed, impact location on the windshield, and head impact region effect on brain injuries. There are certainly other influence factors such as vehicle front shape [43], which could be taken into consideration in future studies.

\section{Conflicts of Interest}

The authors declare that there are no conflicts of interest regarding the publication of this paper.

\section{Acknowledgments}

This work is financially supported by start-up funds of "The Recruitment Program of Global Experts" awardee from Beihang University (YWF-16-RSC-011) and Beijing Municipal Science \& Technology Commission (Grant no. Z161100001416006).

\section{References}

[1] K. Boniface, M. P. McKay, R. Lucas, A. Shaffer, and N. Sikka, "Serious injuries related to the Segway ${ }^{\circledR}$ personal transporter: a case series," Annals of Emergency Medicine, vol. 57, no. 4, pp. 370-374, 2011.

[2] J. R. Elliott, C. K. Simms, and D. P. Wood, "Pedestrian head translation, rotation and impact velocity: the influence of vehicle speed, pedestrian speed and pedestrian gait," Accident Analysis \& Prevention, vol. 45, pp. 342-353, 2012. 
[3] V. S. Alvarez and S. Kleiven, "Importance of windscreen modelling approach for head injury prediction," in 2016 IRCOBI Conference Proceedings - International Research Council on the Biomechanics of Injury, 2016, pp. 813-830, Malaga, Spain, 2016.

[4] M. Fahlstedt, B. Depreitere, P. Halldin, J. Vander Sloten, and S. Kleiven, "Correlation between injury pattern and finite element analysis in biomechanical reconstructions of traumatic brain injuries," Journal of Biomechanics, vol. 48, no. 7, pp. 1331-1335, 2015.

[5] J. Xu, S. Shang, H. Qi, G. Yu, Y. Wang, and P. Chen, "Simulative investigation on head injuries of electric self-balancing scooter riders subject to ground impact," Accident Analysis \& Prevention, vol. 89, pp. 128-141, 2016.

[6] J. Xu, S. Shang, G. Yu, H. Qi, Y. Wang, and S. Xu, "Are electric self-balancing scooters safe in vehicle crash accidents?," Accident Analysis \& Prevention, vol. 87, pp. 102-116, 2016.

[7] J. Zhang, H. Du, and C. Ma, Automotive Design for Crash Safety, Tsinghua University Press, Beijing, China, 2010.

[8] J. Xu, Y. Li, X. Chen et al., "Characteristics of windshield cracking upon low-speed impact: numerical simulation based on the extended finite element method," Computational Materials Science, vol. 48, no. 3, pp. 582-588, 2010.

[9] J. Yao, J. Yang, and D. Otte, "Investigation of head injuries by reconstructions of real-world vehicle-versus-adult-pedestrian accidents," Safety Science, vol. 46, no. 7, pp. 1103-1114, 2008.

[10] K. Mizuno, D. Ito, R. Yoshida et al., "Adult headform impact tests of three Japanese child bicycle helmets into a vehicle," Accident Analysis \& Prevention, vol. 73, pp. 359372, 2014.

[11] B. Mueller, C. Farmer, J. Jermakian, and D. Zuby, "Relationship between pedestrian headform tests and injury and fatality rates in vehicle-to-pedestrian crashes in the United States," Stapp Car Crash Journal, vol. 57, pp. 185-199, 2013.

[12] Y. Okamoto, T. Sugimoto, K. Enomoto, and J. Kikuchi, "Pedestrian head impact conditions depending on the vehicle front shape and its construction-full model simulation," Traffic Injury Prevention, vol. 4, no. 1, pp. 74-82, 2003.

[13] S. Zhao, L. R. Dharani, L. Chai, and S. D. Barbat, "Dynamic response of laminated automotive glazing impacted by spherical featureless headform," International Journal of Crashworthiness, vol. 11, no. 2, pp. 105-114, 2006.

[14] J. Xu, Y. Sun, B. Liu et al., "Experimental and macroscopic investigation of dynamic crack patterns in PVB laminated glass sheets subject to light-weight impact," Engineering Failure Analysis, vol. 18, no. 6, pp. 1605-1612, 2011.

[15] T. Pyttel, H. Liebertz, and J. Cai, "Failure criterion for laminated glass under impact loading and its application in finite element simulation," International Journal of Impact Engineering, vol. 38, no. 4, pp. 252-263, 2011.

[16] S. Mukherjee, A. Chawla, P. Mahajan et al., "Modelling of head impact on laminated glass windshields," in Proceedings of the 2000 International IRCOBI Conference on the Biomechanics of Impact, September 20-22, 2000, pp. 323-334, Montpellier, France, 2000.

[17] J. Mordaka, S. Kleiven, M. van Schijndel-de Nooij et al., “The importance of rotational kinematics in pedestrian head to windshield impacts," in Proceedings of IRCOBI Conference, pp. 83-94, Maastricht, Netherlands, 2007.

[18] C. K. Simms, D. P. Wood, and D. G. Walsh, "The relationship between vehicle impact speed and pedestrian and cyclist projection distance," in Pedestrian and Cyclist Impact, Springer, Dordrecht, Netherlands, 2009.

[19] J. Kerrigan, C. Arregui-Dalmases, and J. Crandall, “Assessment of pedestrian head impact dynamics in small sedan and large SUV collisions," International Journal of Crashworthiness, vol. 17, no. 3, pp. 243-258, 2012.

[20] B. Tass, MADYMO Model Manual, TASS International BV, Helmond, Netherlands, 2010, Release.

[21] Y. Peng, Y. Chen, J. Yang, D. Otte, and R. Willinger, "A study of pedestrian and bicyclist exposure to head injury in passenger car collisions based on accident data and simulations," Safety Science, vol. 50, no. 9, pp. 1749-1759, 2012.

[22] C. K. Simms and D. P. Wood, "Effects of pre-impact pedestrian position and motion on kinematics and injuries from vehicle and ground contact," International Journal of Crashworthiness, vol. 11, no. 4, pp. 345-355, 2006.

[23] A. McLean, C. Kloeden, R. W. Anderson, R. Baird, and M. Farmer, "Data collection and analysis of vehicle factors in relation to pedestrian brain injury," in Proceedings: International Technical Conference on the Enhanced Safety of Vehicles, pp. 1408-1411, Washington, DC, USA, 1996.

[24] B. E. Heinrichs, B. D. Allin, J. J. Bowler, and G. P. Siegmund, "Vehicle speed affects both pre-skid braking kinematics and average tire/roadway friction," Accident Analysis \& Prevention, vol. 36, no. 5, pp. 829-840, 2004.

[25] H. Kimpara, Y. Nakahira, M. Iwamoto et al., "Investigation of anteroposterior head-neck responses during severe frontal impacts using a brain-spinal cord complex FE model," Stapp Car Crash Journal, vol. 50, pp. 509-544, 2006.

[26] J. Xu, Y. B. Li, X. Chen et al., "Automotive windshield pedestrian head impact: energy absorption capability of interlayer material," International Journal of Automotive Technology, vol. 12, no. 5, pp. 687-695, 2011.

[27] TNO Automotive, Manual: MADYMO Human Body Models, TASS International BV, Delft, Netherlands, 2001.

[28] J. Van Hoof, R. De Lange, and J. S. Wismans, "Improving pedestrian safety using numerical human models," Stapp Car Crash Journal, vol. 47, pp. 401-436, 2003.

[29] D. Marzougui, R. R. Samaha, C. Cui, C. Kan, and K. S. Opiela, Extended Validation of the Finite Element Model for the 2010 Toyota Yaris Passenger Sedan, Report, National Crash Analysis Center, George Washington University, Washington, DC, USA, 2012.

[30] Y. Peng, J. Yang, and C. Deck, "Development of head injury risk functions based on real-world accident reconstruction," International Journal of Crashworthiness, vol. 19, no. 2, pp. 105-114, 2014.

[31] K. Shigeta, Y. Kitagawa, and T. Yasuki, "Development of next generation human FE model capable of organ injury prediction," in Proceedings of the 21st Annual Enhanced Safety of Vehicles, pp. 15-18, Stuttgart, Germany, June 2009.

[32] G. Yu, Y. Zheng, B. Feng et al., "Computation modeling of laminated crack glass windshields subjected to headform impact," Computers \& Structures, vol. 193, pp. 139-154, 2017.

[33] X. Zhang, Y. Zou, H. Hao, X. Li, G. Ma, and K. Liu, "Laboratory test on dynamic material properties of annealed float glass," International Journal of Protective Structures, vol. 3, no. 4, pp. 407-430, 2012.

[34] Y. Peng, J. Yang, C. Deck, and R. Willinger, "Finite element modeling of crash test behavior for windshield laminated 
glass," International Journal of Impact Engineering, vol. 57, pp. 27-35, 2013.

[35] B. Liu, T. Xu, X. Xu, Y. Wang, Y. Sun, and Y. Li, “Energy absorption mechanism of polyvinyl butyral laminated windshield subjected to head impact: experiment and numerical simulations," International Journal of Impact Engineering, vol. 90, pp. 26-36, 2016.

[36] J. Xu, Y. Li, B. Liu, M. Zhu, and D. Ge, "Experimental study on mechanical behavior of PVB laminated glass under quasistatic and dynamic loadings," Composites Part B: Engineering, vol. 42, no. 2, pp. 302-308, 2011.

[37] Y. Peng, C. Deck, J. Yang, and R. Willinger, "Modeling and validation of windscreen laminated glass behavior during fracture," in 2012 Third International Conference on Digital Manufacturing \& Automation, pp. 541-544, GuiLin, China, 2012.

[38] L. B. Drew and W. E. Drew, "The contrecoup-coup phenomenon: a new understanding of the mechanism of closed head injury," Neurocritical Care, vol. 1, no. 3, pp. 385-390, 2004.

[39] T. El Sayed, A. Mota, F. Fraternali, and M. Ortiz, "Biomechanics of traumatic brain injury," Computer Methods in Applied Mechanics and Engineering, vol. 197, no. 51-52, pp. 46924701, 2008.

[40] J. Yang, J. Yao, and D. Otte, "Correlation of different impact conditions to the injury severity of pedestrians in real world accidents," in Proceedings of the 19th International Technical Conference Enhanced Safety of Vehicle, Washington, DC, 2005.

[41] D. Sahoo, C. Deck, N. Yoganandan, and R. Willinger, "Influence of head mass on temporo-parietal skull impact using finite element modeling," Medical \& Biological Engineering \& Computing, vol. 53, no. 9, pp. 869-878, 2015.

[42] M. Fahlstedt, P. Halldin, and S. Kleiven, "Comparison of multibody and finite element human body models in pedestrian accidents with the focus on head kinematics," Traffic Injury Prevention, vol. 17, no. 3, pp. 320-327, 2016.

[43] Y. Han, J. Yang, K. Mizuno, and Y. Matsui, "Effects of vehicle impact velocity, vehicle front-end shapes on pedestrian injury risk," Traffic Injury Prevention, vol. 13, no. 5, pp. 507-518, 2012. 


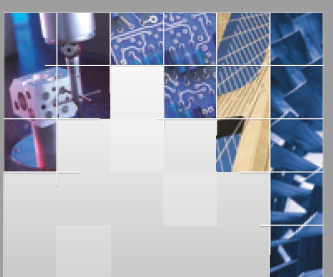

\section{Enfincering}
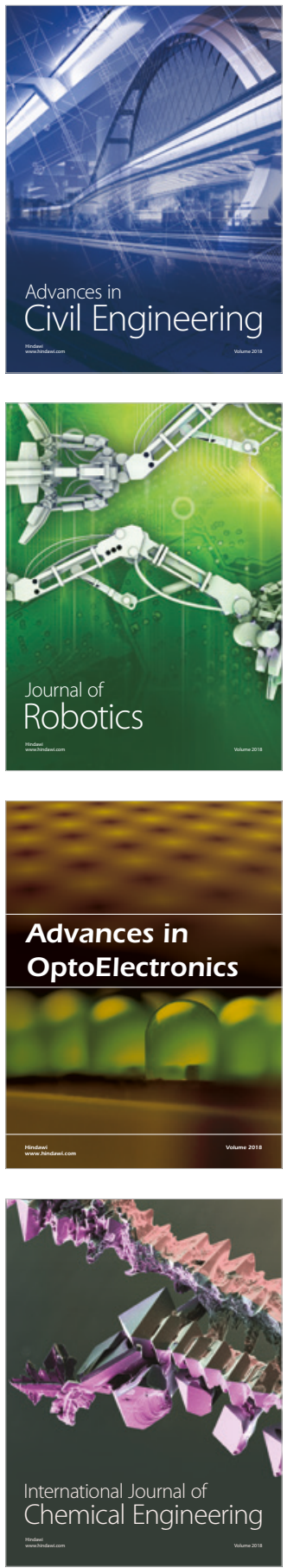

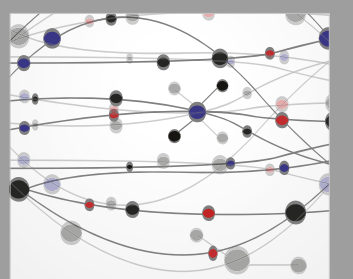

\section{Rotating \\ Machinery}

The Scientific World Journal

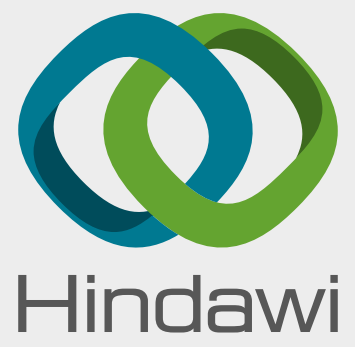

Submit your manuscripts at

www.hindawi.com
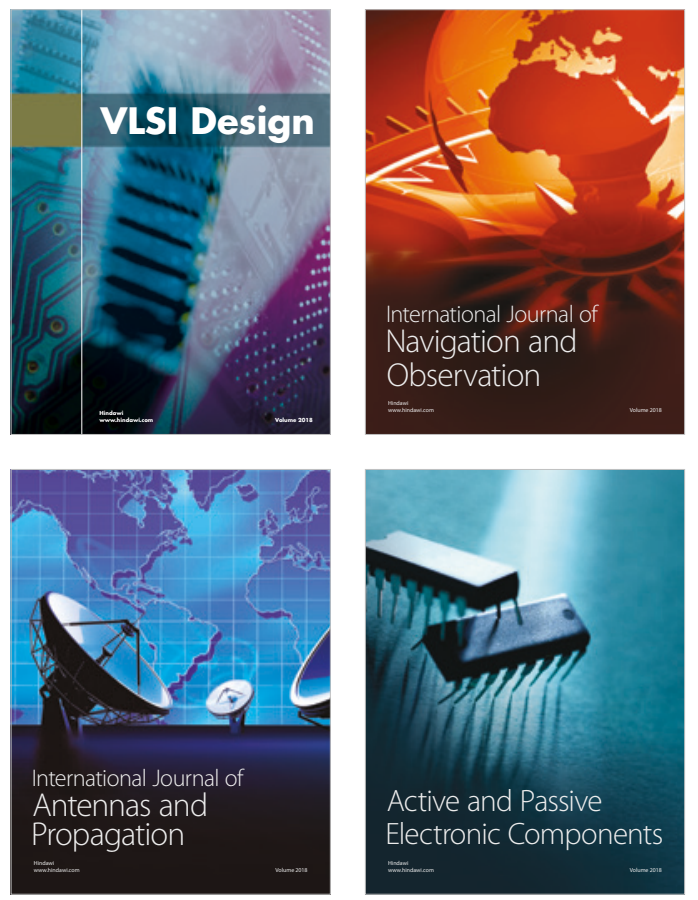
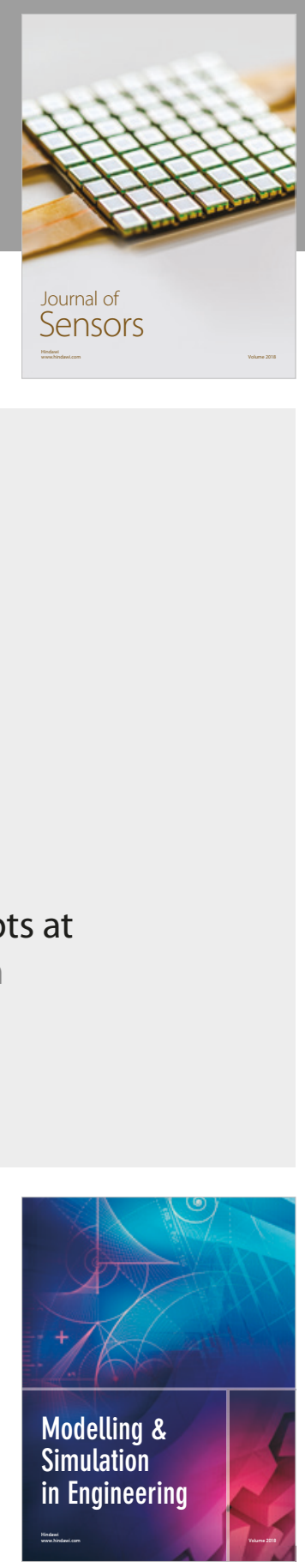

\section{Advances \\ Multimedia}
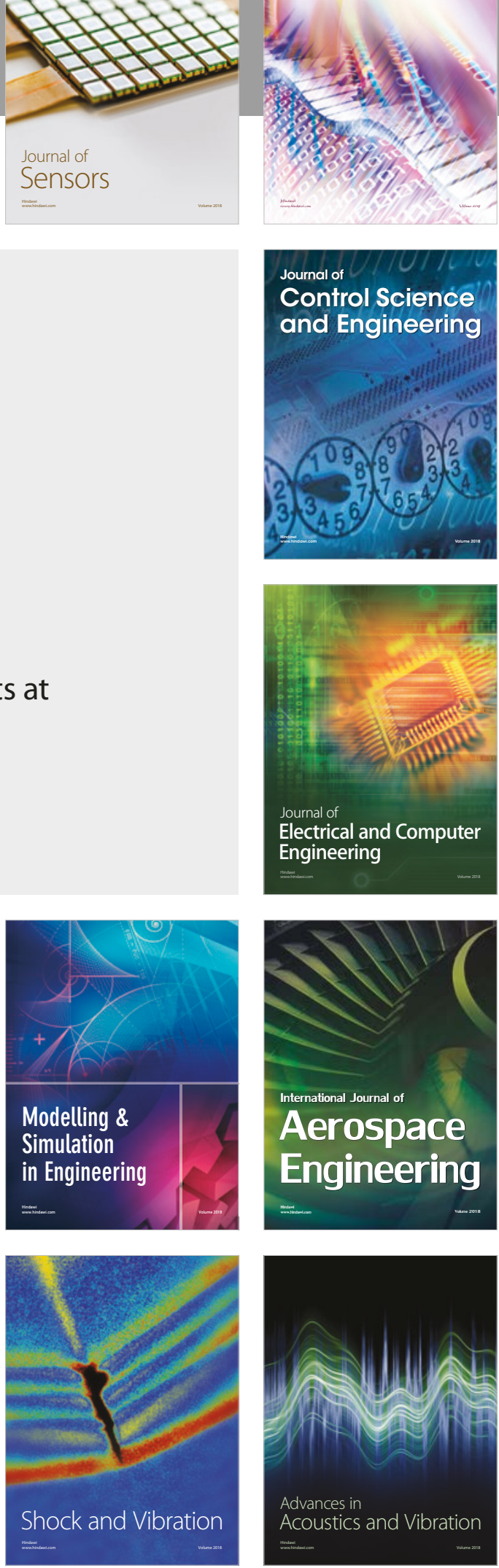